\title{
Mesenchymal Stem Cell-Based Therapies for Parkinson's Disease: Progress, Controversies and Lessons for the Future
}

\section{Melissa L.M. Khoo, Helen Tao and David D.F. Ma*}

Blood Stem Cells and Cancer Research, St Vincent's Centre for Applied Medical Research, and The University of New South Wales, Sydney, New South Wales 2010, Australia

\begin{abstract}
Scientific and clinical research interest in mesenchymal stem cells (MSCs) has increased exponentially since the identification of MSCs in the bone marrow. It is now recognized that MSCs possess the in vitro characteristics of stem cells with the abilities to proliferate, symmetrically divide, and produce multi-lineage mesodermal derivatives, making MSCs attractive candidates for use in potential cellular therapies. Furthermore, MSCs can be relatively easily isolated and expanded in culture with low tumorigenicity and teratoma formation, and have been reported to display immunomodulatory properties that may be advantageous in clinical transplantation. Discovery of the ability of MSCs to differentiate into cells of non-mesodermal tissues, particularly neural cells, has also raised the possibility of utilizing MSCs in regenerative and reparative therapies for neurological disorders. However, a number of hurdles remain to be resolved, including conflicting findings concerning the capacity of MSCs to suppress immune responses and contribute to multiple tissue lineages, highlighting the need for a greater understanding of mechanisms underlying the observed phenomena. In this review we will discuss: (1) recent advances in our understanding of MSC plasticity/transdifferentiation and immunomodulatory properties; (2) evidence for cell-based therapies, in particular MSC-based therapies for Parkinson's disease; and (3) current challenges and potential strategies for the utilization of MSCs in the treatment of Parkinson's disease.
\end{abstract}

\section{Introduction}

Evidence for the existence of a stem cell (SC) population within the bone marrow (BM) that produced non-hematopoietic progeny emerged in the mid-1960's with the pioneering work of Friedenstein and colleagues [1-3]. These studies demonstrated the occurrence of in vivo osteogenesis in transplants of $\mathrm{BM}$, as well as clonal fibroblast colony formation in vitro in monolayer culture (also known as colony forming unit - fibroblastic formation). In addition, this work described a rudimentary technique for isolating the mesenchymal stem cell (MSC) fraction from BM by adherence to cultureware and removal of non-adherent hematopoietic cells [3,4]. These findings, together with those of several independent studies, showed that MSCs were multipotent and differentiated into cells of the mesodermal lineage, including osteoblasts [5-9], chondroblasts $[5,10,11]$, adipocytes $[7,12]$ and myoblasts [13].

Since these initial reports, scientific and clinical research interest in MSCs has increased exponentially. It is now recognised that MSCs possess the in vitro characteristics of SCs with the ability to proliferate, symmetrically divide, and produce multi-lineage mesodermal derivatives, making MSCs an attractive candidate for use in potential cellular therapies. MSCs exhibit further promising qualities for regenerative medicine, including relatively easy isolation from small aspirates of BM, as well as relatively easy expansion in culture with low tumorigenicity and teratoma formation. Furthermore, MSCs have been reported to display immunosuppressive properties that are advantageous for allogeneic transplantation [14-16], and in ideal settings, autologous transplantation is also possible. In addition, subpopulations of MSCs have been reported to be capable of differentiation to non- mesodermal lineages [17-28], indicating the potential application of MSCs in a wider range of diseases. However, conflicting findings concerning the capacity of MSCs to suppress immune responses and contribute to multiple tissue lineages, highlights the need for a greater understanding of the mechanisms underlying the observed phenomena.
In this review we will discuss: (1) recent advances in our understanding of MSC plasticity/transdifferentiation and immunomodulatory properties; (2) evidence for cell-based therapies, in particular MSC-based therapies for Parkinson's disease (PD); and (3) current challenges and potential strategies for the utilization of MSCs in the treatment of PD.

\section{Lineage Conversion Potential of BM-Derived MSCs}

The traditional model of embryonic development (Figure 1) centres upon a strict hierarchy of SC subsets that display progressive and orderly differentiation in a unidirectional manner, finally culminating in a terminally differentiated cell type [29-36]. Central to this view is the early specification of cells during development into the three embryonic germ layers in the course of gastrulation. The segregation of cells into each germ layer was thought to be an irreversible event, and subsequent tissue regeneration and cell replacement were believed to occur through tissue-resident SCs only capable of generating mature cell types of that tissue. However, these established paradigms have been challenged in the past decade with reports demonstrating the surprising ability of adult SCs to cross lineage boundaries, bringing about a remarkable evolution in the field of SC biology [29-38].

In particular, an increasing number of reports, from our laboratory

*Corresponding author: David D. F. Ma, Blood Stem Cells and Cancer Research, St Vincent's Centre for Applied Medical Research, Darlinghurst, NSW 2010, Australia, Tel: 612-83822378; Fax: 612-8382 2645; E-mail: d.ma@amr.org.au

Received October 15, 2011; Accepted November 27, 2011; Published December 01, 2011

Citation: Khoo MLM, Tao H, Ma DDF (2011) Mesenchymal Stem Cell-Based Therapies for Parkinson's Disease: Progress, Controversies and Lessons for the Future. J Stem Cell Res Ther S2:005. doi:10.4172/2157-7633.S2-005

Copyright: (c) 2011 Khoo MLM, et al. This is an open-access article distributed under the terms of the Creative Commons Attribution License, which permits unrestricted use, distribution, and reproduction in any medium, provided the original author and source are credited. 


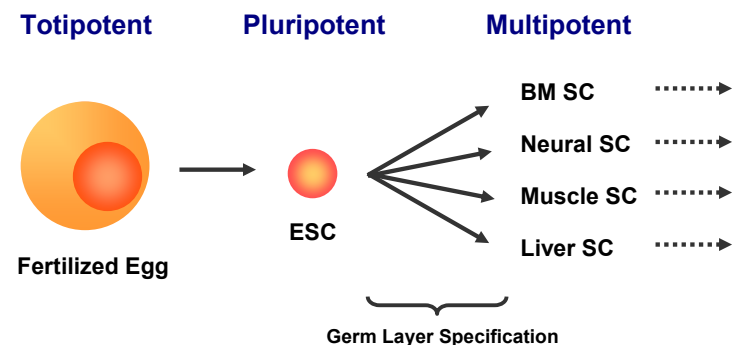

Potential

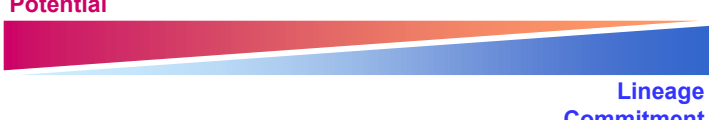

Commitment

Figure 1: Stem cell developmental potential. Stem cells (SCs) are typically classified according to developmental potential, with pluripotent embryonic SCs (ESCs) possessing the greatest capacity for differentiation. Multipotent tissuecommitted SCs are restricted to producing cell types of the tissue from which the SCs are derived. A long-held belief of the process of SC commitment is that it proceeds unidirectionally from left to right, with decreasing potential and increasing lineage commitment. More recently, the extent of lineage commitment of tissue SCs has been challenged by findings of transdifferentiation of cells from one lineage to a different lineage under certain circumstances, giving rise to the concept of adult SC plasticity. BM, bone marrow.

and others, have shown MSCs to be capable of differentiation into a wide range of non-mesodermal cell types both in vitro and in vivo, including ectodermal neuronal and glial cells [17-26], as well as endodermal hepatic cells $[23,27,28]$. These findings have challenged the extent of lineage commitment of MSCs, and together with similar findings in other adult SC populations, have suggested the potential of adult SCs to be capable of transdifferentiation.

While generating great interest in the potential therapeutic value of these cells, observations of MSC multi-lineage differentiation challenge the long-held dogma of irreversible tissue specification during development, and this remains a highly controversial area. It is generally accepted that more rigorous and consistent scientific evidence is necessary to verify these claims before the basic tenets of developmental biology are discarded [29,35]. It has also been proposed that higher standards of evidence should be established for demonstrating adult SC transdifferentiation [29].

The controversy surrounding the MSC plasticity debate has been further fuelled by recent findings that MSCs not only acquire nonmesodermal marker expression following exposure to differentiation conditions, but also express genes and proteins of heterologous lineages prior to differentiation, leading to the suggestion that MSCs possess a "multidifferentiated" or "pluridifferentiated" phenotype [18,19,26,3951]. Whilst, only one study has detected endodermal gene expression in undifferentiated MSCs [41], numerous reports have demonstrated that rodent and human MSCs (hMSCs) express ectodermal markers before differentiation, in particular those of the neural lineage [18,19,26,3945,47-51]. In addition, rat and murine MSCs have recently been found to express germ-line specific and pluripotency markers, including protamine 2, POU5F1 (POU class 5 homeobox 1; also known as OCT3/4) and zinc finger protein 42 homolog (also known as REX1) $[23,41,50]$.

The significance of these findings is three-fold: firstly, it reveals the necessity of ascertaining the basal levels of lineage marker expression by undifferentiated MSCs, and also uncovers possible repercussions for previous reports claiming transdifferentiation without examining expression levels prior to commencement of differentiation; secondly, these findings provide additional support for the propensity of MSCs to undergo neural differentiation, by demonstrating the ease with which neural properties are spontaneously expressed by MSCs; and thirdly, the constitutive expression of both mesodermal and ectodermal phenotypes suggests that MSCs have a "multidifferentiated"[41] or "pluridifferentiated"[42] phenotype.

\section{Neural Differentiation Capacity of MSCs In Vivo}

The prospect of using MSCs in autologous transplantation therapies provides the advantages of overcoming the ethical issues and constraints associated with the acquisition of other types of donor tissue and embryonic SCs (ESCs), and circumvents the need for antirejection drugs and the possibility of transplant rejection. Additionally, transplantation of MSCs is not associated with teratoma formation, unlike ESC transplantation. These factors, and the abilities to expand MSCs relatively easily in culture, as well as to differentiate MSCs into many cell types in vitro, clearly make these cells attractive for potential cell-based patient-specific therapies. The fate of MSCs after transplantation in vivo has been investigated widely, with much interest garnered through reports of MSC-mediated disease improvement in experimental animal models. However, despite recent progress in our understanding, much remains to be determined concerning the in vivo behaviour and function of MSCs.

The ability of MSCs to contribute to particular organ systems has also been the focus of intense investigation. Studies have examined the potential of MSCs to integrate and differentiate after transplantation into normal tissue, as well as developing and injured post-natal tissue. Numerous reports have now described the remarkable efficacy of MSCs in ameliorating damage caused by injury and disease in a wide range of organs and tissues. The mechanisms underlying the observed improvements are yet to be clearly defined; however, transdifferentiation and replacement of damaged cells, secretion of trophic factors, interaction with endogenous host cells, alteration of immune responses, or a combination of these, have been proposed to be involved.

The majority of initial reports demonstrating neural engraftment and restoration by MSCs examined direct intracerebral transplantation of cells into neural regions, including the corpus striatum of normal albino rats [52], the lateral ventricles of neonatal mice [17], the ventricles of embryonic rats in utero [22], and the ischemic boundary zones in rat models of cerebral ischemia [20,21]. Injection of MSCs into uninjured animal models resulted in engraftment, migration along known neural SC (NSC) migratory pathways, incorporation into successive layers of the brain, and phenotypic expression of markers in a manner suggesting the involvement of region-specific signals within the different neural microenvironments to produce characteristics of radial glia, subventricular zone progenitors, migratory cells, parenchymal neurons, and glia [17,22,52]. In addition, Azizi, et al. [52] found an approximate MSC engraftment rate of $20 \%$, loss of COL1A1 and fibronectin production by MSCs post-transplantation, and lack of an inflammatory response or rejection of grafted cells. MSCs also exhibited long-term survival at 1 and 2 postnatal months when infused in rat ventricles in utero at embryonic day 15.5 , and were detected in distant locations throughout the brain, including the olfactory bulbs, rostral migratory stream, frontal, parietal and occipital cortices, hippocampus, dentate gyrus, and the telencephalic ventricular and subventricular zones [22]. 
In experimental models of stroke, intracerebral MSC transplantation was found to result in significant recovery of motor and somatosensory deficits [20,21,53]. In these studies MSCs were observed to survive and migrate along white matter tracts, as well as differentiate to express neural phenotypic proteins, including astrocytic marker glial fibrillary acidic protein (GFAP), oligodendrocytic marker GALC (galactosylceramidase), and neuronal markers neuronal nuclear antigen (NeuN), microtubule-associated protein (MAP)-2, $\beta$ tubulin III, neuron-specific enolase (NSE), and neurofilament proteins, when grafted into the ischemic brain microenvironment. However, while behavioural improvement was detected, the grafted cells did not reestablish a normal tissue cytoarchitecture, with Zhao and colleagues noting that grafted cells displayed a spherical morphology with few processes. From these observations the authors suggested that cell replacement and integration into host circuitry may not be responsible for functional recovery, and this could instead be mediated by trophic factor secretion by MSCs, or by host cells in response to interaction with MSCs [20,21]. Li et al. [54] also demonstrated functional improvement following administration of MSCs via an intracarotid arterial route in a rat middle cerebral artery occlusion model of cerebral ischemia. MSCs were observed throughout the ischemic region in middle cerebral artery territory and in multiple areas of the ipsilateral hemisphere, however, more than $90 \%$ of MSCs were localized in the ischemic core and boundary zone. In addition, approximately $10 \%$ of MSCs in the ipsilateral hemisphere were observed to express GFAP, and $1 \%$ expressed MAP-2, suggesting possible differentiation in vivo towards astrocytes and neurons respectively. Furthermore, the results of this study suggested that intra-arterial administration of MSCs was superior to using an intracerebral route, and transplantation of MSCs did not appear to evoke an inflammatory response. However, the mechanisms underlying the observed neurological recovery remained undefined, although the authors commented that it was unlikely to be due to the apparent adoption of a neural phenotype by MSCs, and could be related to trophic factors produced by MSCs or interaction of MSCs with the host brain [54]. Intracerebral and intravenous transplantation of MSCs into rodent models of traumatic brain injury have also yielded successful results with observations of neurological improvement in the recipient animals [55-58]. Promising outcomes have also been obtained in animal models of PD following transplantation of MSCs (discussed later in greater detail). Collectively these studies highlight MSCs as a promising therapeutic modality for degeneration, ischemia and injury of the nervous system, and are indicative of the ability of MSCs to respond to specific signals in different microenvironments in vivo.

\section{Neural Differentiation Capacity of MSCs In Vitro}

A wide variety of methods for neural differentiation of MSCs have been investigated, with some studies yielding promising results, including the induction of neural gene and protein expression and, in some cases, action potential generation. However, like many areas in the field of SC research, much remains to be determined.

The generation of neuroectodermal-like derivatives from MSCs in vitro is typically achieved through manipulation of the culture microenvironment. In general, at the commencement of neural differentiation, the MSC expansion medium is altered or substituted with culture media, supplements and coating substrates characteristically used in neural cell culture. Depending on whether a specific neural cell type is desired, a range of different supplements and substrates have been employed. Surface coating substrates utilized in MSC neural differentiation include fibronectin [23,24,26,59], polyD-lysine [60,61], poly-L- lysine [25,62,63], poly-L-lysine/laminin [64], poly-ornithine [43] and poly-L- ornithine/laminin [65].

The main approaches taken for MSC neural induction primarily involve the use of chemicals, growth factors and/or signalling molecules, conditioned media, or co-culture systems. On a lesser scale, some studies have employed a genetic engineering approach, whilst other protocols have combined various aspects of the different approaches.

\section{Neural differentiation by chemical induction}

Rapid in vitro transformation of human and rat MSCs into neuronal-like cells using a simple chemical treatment protocol was first reported by Woodbury and colleagues [19]. This study proposed that treatment with pre-induction media, containing Dulbecco's Modified Eagle's Medium (DMEM), 20\% FBS, $1 \mathrm{mM} \beta$-mercaptoethanol (BME) and Fibroblast Growth Factor (FGF)-2 for 24 hours, followed by neuronal induction media composed of DMEM, $\%$ dimethylsulfoxide (DMSO), and $200 \mu \mathrm{M}$ butylated hydroxyanisole (BHA) produced cells exhibiting neuronal morphology and protein expression (NSE, NF-M and Tau) in a very short period (changes observed as early as $60 \mathrm{~min}$ to 3 hours) [19]. This procedure was also used in a neurosphere formation protocol [65], which was later optimized with the addition of $10 \mu \mathrm{M}$ forskolin, N-2 supplement, $2 \mathrm{mM}$ VPA, $5 \mathrm{nM} \mathrm{K252A}$, and $10 \mathrm{mM} \mathrm{KCl}$ [66], to yield greater than $70 \%$ morphologic conversion and expression of Tau, NeuN, NSE, and TUC-4 within 24 hours in the absence of mitosis [66].

Induction of early neural progenitors from hMSCs has also been achieved using conditions that increase intracellular cyclic adenosine mono-phosphate (cAMP; $0.5 \mathrm{mM}$ IBMX / $1 \mathrm{mM}$ dibutyryl cAMP (dbcAMP) in DMEM/20\% FBS) [39]. Treatment for 6 days resulted in conversion of $20 \%$ of MSCs to neuronal-like morphology and increased expression of NSE and vimentin protein [39]. A study comparing the Woodbury and Deng methods found a higher percentage of neuronlike cells generated from the Woodbury protocol, however, this method also yielded a much higher degree of cell death at $53 \%$ of total cells, compared to less than $5 \%$ cell death in the Deng protocol [67]. Alternative techniques that have been reported for hMSC neural differentiation include the application of $10^{-3} \mathrm{M} B M E+/-5 \times 10^{-7} \mathrm{M}$ all-trans-retinoic acid (RA) to attain nestin (NES), NSE, NeuN and $\beta$ tubulin III protein expression within 5 hours [68], and treatment with $3 \mu \mathrm{M}$ 5-bromo-2- deoxyuridine (BrdU) for 3 weeks to increase hMSC multi-lineage differentiation potential [69].

Recent findings have raised doubts over the phenomenon observed during chemical induction and question whether these changes occur through true differentiation processes or through alternative cellular events. The factors underlying these concerns include the seemingly unrealistic time frame of the observed changes, which occurred rapidly over several hours, as well as the lack of neurite growth cone formation with development of neuronal morphology, and the high degree of cell death accompanying the induction process. Recent independent studies using chemical neuronal induction techniques, in particular the DMSO/BHA and IBMX/dbcAMP methods, were unable to reproduce the results of the original studies $[26,46,49,70-73]$. Furthermore, the morphological changes and increases in certain neuronal markers elicited by chemical exposure were demonstrated to be due to cellular toxicity, cell shrinkage and disruption of the actin cytoskeleton in response to environmental stress, rather than complex regulated cellular differentiation processes [46,70-72]. Observations of similar 
cellular responses by a range of cell types, including primary fibroblasts, HEK293 cells and NIH3T3 cells [49,70-72], and the lack of de novo neural- specific protein translation [72,73], further substantiated these results.

\section{Neural differentiation by cytokine and signalling molecule induction}

Different combinations of cytokines and signalling molecules have been utilized for MSC neural differentiation in attempts to mimic the physiological environment thought to drive in vivo neural development. Additionally, clues garnered from the culture requirements of NSCs have also been implemented. Sanchez-Ramos and colleagues [18] conducted the first study examining cytokine and signalling molecule induction of MSCs toward neural-like cells. This work demonstrated that human and mouse MSCs cultured with $10 \mathrm{ng} / \mathrm{mL}$ epidermal growth factor (EGF) or $0.5 \mu \mathrm{M} \mathrm{RA}$ and $10 \mathrm{ng} / \mathrm{mL}$ brain-derived neurotrophic factor (BDNF) could be induced toward a neuronal phenotype [18]. These factors caused large flat fibronectinpositive MSCs to transform into smaller ovoid or spindle-shaped cells, which expressed neural markers and decreased expression of fibronectin [18]. Shortly afterwards, combined stimulation with FGF2, RA and fibronectin substrate was found to yield a significant increase in expression of neuronal lineage marker NF-M from $<1.0 \%$ to $40 \%$ in hMSCs [59]. This combination proved to be the most effective in generating NF-M expression, however, the neurofilament proteinexpressing cells obtained were considered to be immature neuronal lineage progenitors, since action potential-like responses could not be observed in whole cell patch-clamp studies [59].

Experiments conducted in our laboratory with hMSCs have utilized FGF-2, EGF, platelet-derived growth factor (PDGF) and fibronectin surface coating to produce a stable neuronal-like phenotype that is maintained for up to 3 months in vitro [26]. Changes in cell morphology were observed at 2 weeks post-cytokine induction, with the majority (80-95\%) of cells displaying retraction of the cytoplasm towards the nucleus, formation of refractile cell bodies and development of long branching processes [26]. Additionally, increased expression of neuronal markers, including NF-M, NSE, $\beta$ tubulin III, MAP-2 and Tau, were detected post-induction, and neuronal-like cells also expressed neurotransmitters or associated proteins, such as GABA, tyrosine hydroxylase $(\mathrm{TH})$ and serotonin, suggesting generation of GABAergic, dopaminergic and serotonergic neuron-like cells [26]. Significantly, this work also showed in parallel experiments using sister cultures of MSCs that growth factors were capable of inducing a neuronal-like phenotype in MSCs, while chemical agents elicited changes that were not associated with physiological development and also caused cell death after 48 hours [26].

Alternative combinations tested include EGF, FGF-2, RA and nerve growth factor (NGF) in mouse MSCs, for production of cells with neuronal-like processes and neuronal marker expression (NeuN, MAP-2, Tau, and synaptic function-associated proteins, including synaptophysin, GABA, $\alpha 1 \mathrm{~A}$ and $\alpha 1 \mathrm{~B}$ calcium channel subunits and NR2A glutamate receptor subunits), albeit in the absence of appropriate intracellular localisation [60]. Whereas, the MAPC subset of the MSC population of rodents have been stimulated sequentially with FGF2, followed by FGF-8, and finally BDNF, resulting in a more mature neural phenotype than stimulation with FGF-2 alone [23]. MSCs stained positively with markers for neurons (neurofilament-200;68\%), astrocytes (GFAP; 15\%) and oligodendrocytes (GALC; 12\%) when cultured with FGF-2 alone, but with the sequential cytokine induction approach, mature neuronal markers for dopamine (DA)-containing neurons (30\% dopa decarboxylase and $\mathrm{TH}$ positive), serotonincontaining neurons (20\% serotonin positive) and GABA-containing neurons (50\% GABA positive), as well as MAP-2 and Tau could be detected [23]. In a later study, with the addition of sonic hedgehog (SHH) to the second step (FGF-8) of the differentiation protocol, murine MAPC-derived neuron-like cells were demonstrated to acquire functional voltage-gated sodium channels; however, this could only be achieved after co-culture with astrocytes [24].

Interestingly, several studies have also reported the formation of neurosphere-like aggregates from rat and human MSCs that are morphologically similar to those produced by NSCs $[25,43,65,74]$. Suzuki, et al. induced neurosphere formation in rat MSCs using FGF2 alone, followed by neurosphere differentiation via plating spheres onto poly-L-ornithine/laminin coated surfaces with media containing FGF-2 for the first 1-2 days, followed by BDNF for up to 7 days [65]. Whereas, Hermann and colleagues observed neurosphere-forming capacity with addition of FGF-2 and EGF to hMSC cultures, and also induced terminal neural differentiation by plating onto poly-Llysine-coated surfaces and treating with RA and BDNF for neuronal differentiation, or RA and PDGF for glial differentiation [25]. Furthermore after neuronal differentiation, neurosphere-derived cells were found to be capable of DA production and potassium-dependent release. However, neither mature MAP-2ab-positive neurons nor THpositive/DA producing cells were obtained through this protocol, and cells continued to express pluripotency marker POU5F1 [25]. Sphere formation by hMSCs was initiated in a similar manner by Suon, et al., through suspension culture and supplementation with EGF and FGF-2 [74]. However, for further differentiation neurosphere-like aggregates were plated onto poly-ornithine/laminin-coated surfaces in serum-free medium containing IBMX, forskolin and TPA (4 $\beta-12-\mathrm{O}-$ tetradecanoylphorbol 13-acetate) for 3 hours, followed by dbcAMP for 7 days, producing neuronal-like cells with GABAergic-like and dopaminergic-like traits [74]. While NES expression was found by another study to be necessary for neurosphere formation by rat MSCs [43].

\section{Neural differentiation by conditioned media or co-culture systems}

Co-culturing of MSCs with a variety of neural cell types or treatment with neural cell- conditioned media has also been performed in attempts to achieve a more mature neuronal phenotype. The earliest report of cytokine- and signalling molecule-based neural induction of MSCs also demonstrated that co-culturing murine MSCs with primary fetal murine midbrain cells provided enhanced differentiation [18] After co-culturing, the number of MSC-derived cells expressing NeuN and GFAP increased by at least two-fold, supporting the hypothesis that cell-to-cell contact plays an important role in MSC differentiation, in addition to signalling with cytokines and trophic factors [18].

Astrocytes have been utilized in co-culture and conditioned media experiments [24,64], since hippocampus-derived astrocytes have been shown to have a role in instructing neuronal fate specification of NSCs and promoting neuronal maturation and functional synapse formation $[75,76]$. Application of astrocyte-conditioned medium was found to generate greater process elaboration in neuronal-like cells and fewer astrocyte-like cells [64]. While, co-culturing with fetal brain astrocytes was found to result in prolonged survival, and acquisition of more elaborate axonal morphology and electrophysiological properties typical of neurons, which was only observed following co-culturing, 
and not with exposure to astrocyte-conditioned medium or cytokine induction alone [24].

Neural SCs have also been employed in co-culture systems for rodent MSC neural differentiation [43,77]. Varied results have been obtained, although, in general, NSC, glial and neuronal marker expression and morphological changes were observed. A later study further showed that rat MSCs co-cultured with murine cerebellar granule neurons expressed neuronal markers, including Tuj1 and NeuN, and displayed electrophysiological properties of immature neurons, such as singleaction potential generation and response to several neurotransmitters [78]. The microenvironment created by tissue explant cultures has also been utilized for examining neuronal differentiation from murine MSCs $[61,79]$. Culturing MSCs in the presence of an organ of Corti explant and neural induction medium appeared to promote survival, proliferation and acquisition of a sensory neuron-like phenotype, with expression of defined sensory neuron markers Brn3a, glutamate receptor 4, and calretinin [61]. An organotypic hippocampal slice co-culture model has also been employed, in which neuron-like cells were obtained that formed network-like connections and axon-like processes that penetrated into the hippocampal tissue [79].

\section{Neural differentiation by genetic engineering}

A genetic engineering approach has also been employed to attain MSC-derived neural-like cells through the over-expression of specific genes known to be important for neural development and function. Genes that have been over-expressed in MSCs for generation of neural cells include: Noggin [80], the Notch intracellular domain (NICD) [81], and the BDNF gene [82].

Transfection of MSCs with the Noggin gene caused cells to aggregate and detach from culture surfaces, and form non-adherent neurosphere-like clusters [80]. Plating of the cluster-forming cells onto poly-L-ornithine/fibronectin-coated surfaces and growth in medium containing a cytokine cocktail, elicited differentiation into neuronallike cells, with greater than $50 \%$ of cells expressing MAP-2, and evidence of calcium influx in response to depolarizing stimuli [80]. Transfection of MSCs with NICD together with application of FGF-2, ciliary neurotrophic factor (CNTF), forskolin, and in some cases glial-derived neurotrophic factor (GDNF) or BDNF/NGF, resulted in the generation of neuronal-like cells capable of electrophysiological activity, as well as behavioral improvement in an animal disease model [81]. Whilst, combination of $B D N F$ gene transfection with RA induction produced cells with significantly increased expression of neural markers, NES, NeuN, O4 and GFAP, and the ability to generate voltage dependent $\mathrm{K}+/ \mathrm{Ca} 2+$ currents using the patch clamp technique [82]. However, since clinical application is often the goal of directed differentiation of MSCs toward mature neural cell types, it is desirable to obtain these cells through methods devoid of genetic engineering strategies.

\section{Evidence of neuronal differentiation of MSCs}

The results of the above-mentioned studies, together with studies examining in vivo MSC transplantation, reveal great promise for the eventual use of MSCs in cellular therapies for neurodegenerative diseases. However, recent inconsistent results and findings of MSC fusion with mature cell types have revealed the necessity for further detailed analyses in order to gain a greater understanding of the true nature of MSC multi-lineage differentiation events. Moreover, a number of factors complicate the interpretation of published results, as the methods employed for neural differentiation and assessment of the produced cells are often fragmented and inconsistent [37].
Additionally, many markers used for classifying neural cell types are not entirely neural-specific, and in vitro expansion of MSCs in culture may introduce artifacts [37].

Currently, the majority of studies have relied on morphological, immunological and gene expression changes as evidence of neural plasticity of MSCs. However, several criteria have been proposed to define whether a functional neuron has indeed been generated [83,84]. According to Reh [84], the proposed neuronal cell should be (1) post-mitotic, (2) polarized, with a single axon and multiple dendrites, (3) capable of firing voltage-gated action potentials, and (4) able to communicate with other neurons through synapses, requiring both neurotransmitter release and neurotransmitter receptors. Furthermore, in defining a new neuron, not only should the correct anatomy of a neuron be displayed, but the cell should display appropriate developmental maturation, that is, the anatomical features of a maturing neuron should be matched with the expression of neuronal-specific markers [83]. However, the specificity of markers relies heavily on the quality of the antibody, as a result, markers should only be considered as indicative of neuronal identity, and cannot confirm neuronal identity on their own [83]. Therefore, the ultimate tests for identification of neuronal cells are assessment of the ability to connect and form synapses with other neurons, and to subsequently affect the behavioral function of an animal; these are typically examined through electrophysiological techniques and transplantation into animal disease models with demonstration of graft function through behavioral testing [83]. To date, none of the studies examining MSCderived neuronal-like cells have shown fulfilment of all these criteria.

The expression of neural genes and proteins by undifferentiated MSCs prior to application of differentiation stimuli emphasizes the need for examining basal expression levels in MSCs, and for caution in interpreting results. Therefore, in neuronal differentiation of MSCs it would be necessary to demonstrate significant up-regulation of an already expressed neuronal marker/s, and/or de novo expression of neuronal-specific marker/s. In addition, if genes and proteins from multiple lineages are constitutively expressed in MSCs, it would be expected that concomitant down-regulation of non-neuronal markers should be observed. Expression of NES by MSCs has frequently been reported in the literature as evidence of a NSC-like or neural progenitorlike phenotype, since NES was originally described as a marker of NSCs [85]. However, NES expression has now been documented in a variety of cells and tissues, including developing and regenerating muscle [86-88], newly formed endothelial cells [89-91], epithelial cells of the developing lens [90], and activated hepatic stellate cells [92] In addition, non-neural cells such as chondrocytes, myoepithelial cells and certain fibroblast populations have been reported to express GFAP, neurofilament and/or NSE proteins [93,94]. Phinney and Prockop [37] have also commented that while many reports have shown expression of a wide range of neural proteins in MSC-derived neuron-like cells, only an unbalanced repertoire of neuronal markers has been described, with cells often lacking the functional properties of bona fide neurons. Furthermore, limitations with the current evidence of electrophysiological activity also exist, as those studies which have shown acquisition of neuronal functional properties have not verified the presence of all electrical characteristics of neurons, or are unable to show these attributes [37].

Recently, time-lapse microscopy has been employed for examining the process of neural differentiation from rat and human MSCs using the chemical induction method and serum withdrawal [70-72,95]. Using 
this technique it was shown that the acquired morphological changes after application of BME, DMSO/BHA or serum withdrawal were due to cellular shrinkage rather than new neurite outgrowth, and that there was no motility or further elaboration of the processes remaining after cytoplasmic retraction [70-72,95]. Furthermore, these morphological changes could be reproduced in normal primary fibroblasts, and could be mimicked by drugs that elicit cytoskeletal collapse and disruption of focal adhesion contacts $[71,72,95]$, or by various cellular stressors such as detergents, high-molarity sodium chloride, and extremes of $\mathrm{pH}$ [70].

Nevertheless, cytokine-based neural differentiation has yielded promising results, with an earlier study by our group demonstrating active and dynamic responses by hMSCs to cytokine-induction [96]. We found that cytokine-based induction elicited an entirely distinct cellular response in hMSCs compared with the "simple chemical induction protocol" described by Woodbury and colleagues [19]. Cells exposed to a cytokine cocktail (FGF-2/EGF/PDGF) were highly active and motile, displaying dynamic extension and movement of neuritelike processes and structures similar to neuronal growth cones, as well as the formation of transient branching morphology, as recorded in live cell imaging videos. These observations differed greatly from reports showing that morphological changes generated by chemical induction (DMSO/BHA or IBMX/cAMP) were the result of the cytotoxic effects of added chemicals [46,49,70-73]. In addition, cytokine-induced hMSCs progressively attained neuronal-like morphology over the first week of culture and maintained these changes for at least 1 month in vitro. Viability of cultures was consistently maintained at $>85 \%$ over the course of differentiation, and the time frame of these changes was in terms of days and weeks, rather than hours, and allowed sufficient time for alteration of cellular organization and gene/protein expression, unlike the rapid conversion (within hours) observed with chemical treatment. Furthermore, MSCs could not be maintained in DMSO/BHA serum-free conditions, because of increased cell death (50\% death within 72 hours) and detachment from the culture surface $[26,70]$. Subculturing DMSO/BHA-treated cells was also not possible due to the failure of these cells to re-attach following trypsinization. These findings suggest that the alterations in cell phenotype induced by cytokine-based neuronal differentiation of hMSCs are not simply due to culture artifacts, but can be attributed to active and dynamic cellular processes. With respect to the use of morphological analysis as evidence of MSC neural differentiation, it appears that time-lapse microscopy is a useful technique for ascertaining the validity of morphological changes, and to ensure that any putative axons/dendrites were formed through outgrowth rather than cellular shrinkage.

Another challenging aspect in characterizing MSC neuronal differentiation, involves the identification of MSC-derived neurons after grafting. Much of the difficulty with this is in distinguishing between host and graft cells. Currently, for grafting cells of the same species, identification of donor cells is mainly achieved through the use of genetic modification to label cells (e.g. with GFP or $\beta$-galactosidase), transplanting male donor cells to allow for Y chromosome detection, pre-labelling cells with fluorescent dyes, or using BrdU or tritiated thymidine to label dividing cells before transplantation [83]. In addition, if hMSCs are to be grafted into an animal model, then it is possible to stain for detection of human specific markers such as human nuclear antigen (HNA). Using the above cell identification techniques together with neural-specific markers, therefore, allows identification of grafted cells and an indication of whether neuronal differentiation events have occurred. However, caution should be taken in analyzing tissue-sections using this method, as false double- positive cells may be detected with standard fluorescence microscopic analysis (i.e. singlelabelled cells juxtaposed onto one another). Instead, detailed analysis of tissue sections using high-powered analytical equipment, such as confocal microscopes, would be useful to reduce the likelihood of detecting false double-positive cells [83]. The possibility of cell fusion must also be considered, particularly with in vivo transplantation experiments or in vitro co-culture systems, in which the MSCs are in direct contact with other cell types. The reported frequency of cell fusion events is typically low, however, it has been detected in lethally irradiated animals receiving BM grafts [97,98], and in mouse BM cells co-cultured with mouse ESCs [99]. Nevertheless, cell fusion cannot account for all MSC neural differentiation events, as in vitro studies have shown acquisition of neural phenotypes by MSCs that were not in contact with neural cells.

While much remains to be determined, continued investigations conducted in a meticulous and systematic manner in areas such as MSC prospective isolation, efficient clonal selection, optimal expansion and in vitro differentiation, will undoubtedly provide a great deal of knowledge and understanding for the proper development of therapeutic approaches involving MSCs. Advancements have already been made with an increasing number of studies reporting evidence for the acquisition of electrophysiological properties by MSCs postneuronal differentiation in vitro [100-103]. Functionality has been shown in these studies by demonstrating neurotransmitter synthesis and packaging $[100,101]$, neurotransmitter release in response to depolarizing stimuli $[102,103]$, presence of spontaneous post-synaptic currents $[100,102]$, constitutive DA release [101], and up- regulation of voltage-gated potassium [101] and sodium channels [102].

\section{Immunomodulatory Properties of MSCs}

Further clinical interest in MSCs has been fuelled by an emerging body of data indicating that MSCs possess immunomodulatory properties. MSCs had been long thought of as having an immune privileged status, but are now recognized to possess the dual ability to both suppress and/or activate immune responses, depending on the stimulus to which the cells have been exposed [104,105]. Initially, investigations centred on the immunosuppressive nature of MSCs in relation to T lymphocytes [14-16]. However, increasing evidence has revealed that MSCs may exert effects on a broad range of immune cells, including antigen- presenting cells (APCs) [106-110], natural killer (NK) cells [106,111-115] and B cells [115-118].

\section{Effects of MSCs on T cells}

In vitro studies with human, baboon and murine MSCs have demonstrated that MSCs are capable of inhibiting the proliferation of $\mathrm{T}$ cells induced by allogeneic cells or mitogens such as phytohemagglutinin and concanavalin A $[14,16,119,120]$, as well as the activation of T cells by CD3 and CD28 antibodies [15,120], in a dosedependent manner. Furthermore, MSCs have been reported to escape recognition by cytotoxic T lymphocytes (CTLs), inhibit the formation of CTLs, induce formation of regulatory $\mathrm{CD}^{+} \mathrm{T}$ cells, decrease the secretion of interferon (IFN)- $\gamma$ by $T$ helper $\left(T_{H}\right) 1$ cells and increase interleukin (IL) -4 secretion by $\mathrm{T}_{\mathrm{H}} 2$ cells, favour the differentiation of $\mathrm{CD}^{+} \mathrm{CD} 25^{+}$regulatory $\mathrm{T}$ cells and decrease the alloantigen-specific cytotoxic capacity of CTLs or NK cells $[106,112,114,121]$.

The suppressive effect of MSCs on T cell proliferation was found to be independent of the major histocompatibility complex (MHC) $[15,16]$, with the majority of studies showing involvement of soluble factors secreted by MSCs, such as hepatocyte growth factor (HGF), 
transforming growth factor (TGF)- $\beta 1$, prostaglandin E2 (PGE2), indoleamine 2,3- dioxygenase (IDO; which depletes tryptophan, an essential factor for lymphocyte proliferation), nitric oxide and IL-10 [14,106,112,120-124]. However, due to conflicting data, there remains no consensus on which soluble factors are essential for suppression. In addition, a role for direct cell-to-cell contact mechanisms in MSCmediated suppression has also been described $[15,117]$.

Another possible mechanism of MSC-mediated immune suppression is induction of T cell anergy. MSCs express MHC class I molecules which may activate $\mathrm{T}$ cells, but lack surface expression of costimulatory molecules, such as CD80 and CD86, resulting in MSCs being unable to provide a secondary signal and thereby leaving $\mathrm{T}$ cells anergic $[105,125,126]$. MSCs have been demonstrated to induce division arrest anergy in $\mathrm{T}$ cells, in which $\mathrm{T}$ cell proliferation was inhibited (arrested at $\mathrm{G}_{1}$ phase) and IFN- $\gamma$ production was decreased [118]. However, this condition differed to classical anergy, which can be reversed by exogenous IL-2, as T cell proliferation could not be restored upon addition of exogenous IL-2.

Overall, these studies have been interpreted as indicative of an immunosuppressive role of MSCs, however, it has been acknowledged that the current evidence only shows targeting of $\mathrm{T}$ cell proliferation in vitro rather than $\mathrm{T}$ cell effector function, and therefore may suggest a general non-specific anti-proliferative effect of MSCs [126-128].

\section{Effects of MSCs on professional antigen-presenting cells}

The differentiation, maturation and function of the initiators of the immune response, the professional APCs e.g. dendritic cells (DCs), are also disrupted by MSCs. Several studies have shown that the presence of MSCs significantly inhibited differentiation of both monocytes and $\mathrm{CD}_{3} 4^{+}$progenitors into DCs, and prevented the increase of $\mathrm{CD} 1 \mathrm{a}$, CD40, CD80, CD86 and HLA-DR expression. During maturation, MSCs prevented up-regulation of CD40 and CD86, while mature DCs treated with MSCs also showed reduced CD83 expression, suggesting skewing toward an immature status. Furthermore, exposure to MSCs during differentiation and maturation resulted in cells with decreased capacity for inducing $\mathrm{T}$ cell proliferation, showing that DC phenotype and function are affected by MSCs [108-110]. It has also been reported that hMSCs induce APCs toward a regulatory phenotype, and that the cells produced possess T cell-suppressive properties [107]. Additionally, alterations in DC cytokine production have been demonstrated, with hMSCs found to cause decreased secretion of pro-inflammatory cytokines tumour necrosis factor- $\alpha$ (TNF- $\alpha$ ) and IL-12, and increased production of anti-inflammatory cytokine IL-10 [106-108, 110]. Together these results indicate that MSCs are capable of suppressing DC differentiation and can cause the formation of immature DCs that display a suppressor or inhibitory phenotype [126].

\section{Effects of MSCs on B Cells}

MSCs have also been shown to exert immunosuppressive activities on B cells. Human B cell proliferation was shown to be inhibited by MSCs in vitro, through cell arrest in the $\mathrm{G}_{0} / \mathrm{G}_{1}$ cell cycle phase, prevention of differentiation to antibody-secreting cells as seen by impaired immunoglobulin (Ig)M, IgG and IgA production, and interference with chemotaxis through down-regulation of CXCR4, CXCR5 and CCR7 expression [116]. However, no effect on B cell costimulatory molecule expression and cytokine production was observed, while paracrine secretion of soluble factors was implicated in the mechanism of $\mathrm{B}$ cell suppression. Murine studies have also observed similar findings of inhibition of $\mathrm{B}$ cell proliferation following stimulation with anti-CD40 monoclonal antibody and IL-4 or pokeweed mitogen, with soluble factors playing a role in suppression $[117,118]$. Additionally, co-culturing of $B$ cells from a murine model of systemic lupus erythematosus with allogeneic MSCs resulted in inhibition of B cell proliferation, activation and IgG secretion [129]. However, contradictory data has been reported, which found that $\mathrm{B}$ cell proliferation could only be inhibited by MSCs in the presence of exogenous IFN- $\gamma$ [115]. Nonetheless, these studies suggest that MSCs are capable of modulating B cell functions at multiple levels.

\section{Effects of MSCs on natural killer cells}

Several independent groups have demonstrated that MSCs also inhibit NK cell proliferation in response to IL-2, IL-15 and alloantigens [111,113-115]. However, proliferation of activated NK cells was only partially suppressed by MSCs [111]. Additionally, co-culture with MSCs was found to suppress the effector functions of NK cells. Secretion of cytokines, including IFN- $\gamma$, IL-10 and TNF- $\alpha$, were reduced after culturing in the presence of MSCs [106,113,115,130], and NK cell cytotoxic activity was also impaired $[113,114,130]$. Suppression of cytotoxic activity was shown to be related to the down-regulation of activating NK receptors NKp30 and NKG2D, which are involved in NK cell-activation and target cell killing, and absence of NKp44 activating receptor [130]. However, other studies have found that cytolytic activity is not inhibited in freshly isolated NK cells [112], or was restricted to HLA-class I-expressing targets [113].

Initially, MSCs were thought to escape recognition by NK cells, since it was reported that MSCs were not lysed by killer cell immunoglobulinlike receptor ligand mismatched alloreactive NK cells [112]. However, recent reports have shown that hMSCs are highly susceptible to lysis by activated NK cells, and that this is mediated by activating NK receptors NKp30, NKG2D and DNAM-1 and the expression of the corresponding ligands by MSCs [111,113]. Interestingly, exposure of hMSCs to IFN- $\gamma$ caused protection from NK cell-mediated lysis due to the up-regulation of surface HLA-class I expression [111].

The mechanisms of MSC-mediated NK cell suppression are still under investigation, but soluble factors IDO, PGE2 and TGF- $\beta$ $[113,115,130]$, as well as cell-to-cell contact [113], have been implicated, suggesting the existence of different mechanisms.

\section{MSC immunomodulation in In vivo studies and clinical studies}

The immunosuppressive effects and immunogenicity of MSCs have primarily been demonstrated in in vitro studies, and only a few studies have investigated these properties in in vivo or clinical settings. However, the limited data available at present provides little evidence that donor MSCs are able to engraft after infusion or transplantation $[131,132]$.

In one of the earliest in vivo studies, Bartholomew and colleagues [119] showed that intravenous administration of allogeneic, MHCmismatched MSCs prolonged the survival of allogeneic skin grafts in baboons to 11 days, in comparison with 7 days in controls. Engraftment in multiple tissues and site-specific differentiation of hMSCs has also been reported after intrauterine transplantation in fetuses of sheep, even after development of immunocompetency [133,134].

MSCs have also been found to exert therapeutic effects on severe graft-versus-host disease (GVHD), which was first reported in a landmark case study showing that repeated infusion of MSCs from the patient's HLA-haploidentical mother with cyclosporine treatment, 
completely reversed grade IV acute GVHD of the gut and liver [135]. Additionally, systemic infusion of adipose-derived MSCs has been found to control lethal GVHD in mice, with greater efficiency if MSCs were administered early after hematopoietic SC transplantation, and possible requirement of repeated doses [136]. However, another murine study failed to show any effect of MSC transplantation on the incidence and severity of GVHD, although this may be due to administration of a single MSC dose alone [126,137]. Horwitz, et al. have also administered allogeneic MSCs to children with osteogenesis imperfecta via intravenous infusion and demonstrated potential engraftment, at least for short-term periods of 4-6 weeks [138].

Contrary to these findings, MSCs have been found to be immunogenic in certain transplant scenarios, indicating that MSCs are not intrinsically immune privileged. Xenogeneic transplantation of hMSCs into the myocardium of immunocompetent rats resulted in an intense cellular immune response (primarily macrophage infiltration) and graft rejection [139]. In contrast, myocardial engraftment was seen after transplantation into RNU athymic or tacrolimus-immunosuppressed rats. Furthermore, significant rat lymphocyte proliferation was observed when hMSCs were co-cultured with lymphocytes of rats previously exposed to hMSCs, indicating the presence of a sensitization reaction. Another study examining the effect of MSCs on allogeneic BM transplantation in sublethally irradiated mice found that addition of syngeneic host MSCs significantly enhanced long-term engraftment, whereas infusion of donor-derived MSCs not only failed to prevent rejection, but increased rejection [140]. This study further showed that MSCs were capable of inducing a memory $\mathrm{T}$ cell response after injection into immunocompetent hosts. Together with a previous study showing rejection of allogeneic MSCs after transplantation in MHC-mismatched mice [141], these findings indicate that MSCs can be immunogenic under appropriate circumstances.

\section{Controversy related to MSC immunomodulation}

The precise mechanisms underlying the immunomodulatory properties of MSCs remain largely unresolved, despite being of increasing importance. The currently available data is controversial, and the majority of reports including a clinical study performed by our group [142], have not demonstrated long-term engraftment of donor MSCs. Le Blanc and Ringden [131] have commented that the diversity in findings could be attributed to the use of different techniques for obtaining MSCs, different stimuli, culture conditions, doses and kinetics, and different lymphocyte populations. Furthermore, after in vivo transplantation it has been difficult to detect or recover MSCs from the $\mathrm{BM}$ of recipients, which could be due to a number of reasons, including homing of MSCs to other sites for mediating immune suppression, non-specific lodging in capillary beds of other tissues (particularly pulmonary tissue), the possibility that MSCs exert effects by production of growth factors and die after completion of this role, or perhaps difficulty in detecting MSCs within BM aspirates due to the endosteal location of these cells [126,131].

\section{Overview of Parkinson's Disease}

The development of methods to induce neuronal differentiation of hMSCs has opened the possibility of applying these cells in regenerative or reparative therapies of the central nervous system (CNS). The loss of neurons characterizes many neurodegenerative diseases, such as PD, Alzheimer's disease, and Huntington's disease, and injuries such as stroke, traumatic brain injury, and spinal cord injury. Furthermore, the CNS is known to have a poor capacity for generating new neurons and oligodendrocytes after injury or degeneration, with the adult and aged CNS, in particular, possessing a prevailing non-neurogenic and growth-inhibitory milieu that negatively influences these processes $[143,144]$. For these reasons, therapies endeavoring to replace the damaged or missing neurons and restore some degree of function have been the focus of much attention. Positive outcomes, including neurological recovery, have been observed following transplantation of MSCs into animal models of CNS disorders, revealing MSCs to be a promising therapeutic modality for the treatment of CNS diseases and injuries.

$\mathrm{PD}$ is a chronic neurodegenerative disorder characterized by the progressive loss of nigrostriatal neurons that synthesize the neurotransmitter DA [145]. The cell bodies of affected dopaminergic neurons reside within the substantia nigra pars compacta, while the nerve terminals project rostrally to innervate the striatum (also known as the caudate putamen). Consequently, neuronal degeneration in PD is associated with a reduction in striatal DA content, with the severity of symptoms being proportional to the DA deficiency.

\section{Neuropathological features of Parkinson's disease}

A number of neuropathological features define PD, including the specific loss of pigmented catecholaminergic neurons of the substantia nigra (A9 group of dopaminergic neurons), the presence of Lewy bodies in remaining nigral neurons, and the normal appearance of the striatum [146-149]. The classic macroscopic finding of substantia nigra depigmentation or pallor results from the depletion of neurons which normally contain conspicuous amounts of neuromelanin [147] Lewy bodies are visible as single or multiple, eosinophilic, round to elongated inclusions in the cytoplasm of affected neurons, and are composed of numerous proteins, including misfolded synaptic protein $\alpha$-synuclein, parkin, ubiquitin, synphilin and neurofilaments $[145,147,150]$. Often, these protein aggregates have a dense hyaline core surrounded by a clear halo, and ultrastructurally, are composed of fine filaments densely packed together at the core, but loose at the rim [145,147]. Additionally, Lewy neurites can be observed, which occur when proteinaceous aggregates form in dendrites producing a local swelling [147]. Interestingly, in PD the mesolimbic dopaminergic neurons, which reside in the ventral tegmental area (VTA) adjacent to the substantia nigra pars compacta, are much less affected [147]. Further neurodegeneration also exists in PD beyond that observed in dopaminergic neurons, with degeneration and Lewy body formation evident in noradrenergic (locus coeruleus), serotonergic (raphe), and cholinergic (dorsal motor nucleus of vagus, nucleus basalis of Meynert) systems, and in the cerebral cortex (especially the cingulate gyrus and parahippocampal gyrus), olfactory bulb and autonomic nervous system [145-147]. However, degeneration of dopaminergic neurons of the substantia nigra pars compacta remains the earliest and most consistent neuropathologic feature of PD.

\section{Clinical features of Parkinson's disease}

The clinical features of PD were initially described almost two centuries ago by James Parkinson in 1817 [150-152]. The cardinal symptoms of PD include bradykinesia (slow movement), muscular rigidity and resting tremor, although postural instability, impaired gait, depression, dementia and other motor and non-motor symptoms may also be involved $[146,148,150]$. Of the cardinal symptoms, bradykinesia primarily contributes to the disability experienced by PD patients, whilst tremor is the most conspicuous feature and stigmatizes 
patients as PD sufferers [148]. Degeneration of dopaminergic neurons is well underway by the time symptoms become apparent, with loss of approximately $50 \%$ of nigral dopaminergic neurons and depletion of $70-80 \%$ of DA in the striatum $[150,153,154]$. Estimates from the rates of substantia nigra cell loss suggest that disease onset in PD patients commences approximately 5 years prior to the onset of symptoms [154].

Although the symptoms and pathology of PD have been long identified, the mechanisms underlying the dysfunction and progressive loss of dopaminergic neurons is still poorly defined. Idiopathic PD is usually sporadic, with major risk factors of aging and environmental exposure, but evidence of a genetic component has also been demonstrated with a 2-14 fold increase in relative risk found in close relatives of PD patients, and some concordance between identical twins who develop PD at less than 50 years of age, or when examining subclinical dysfunction of the nigrostriatal dopaminergic system by positron emission tomography (PET) imaging [150,155-158]. Nonetheless, investigation of an environmental cause was the focus of much research, with epidemiological studies showing geographical variation in incidence that appeared to be associated with living in a rural environment, well-water consumption, and exposure to pesticides, herbicides, farming and industrial chemicals [151,155,157,159], and the finding of a PD syndrome resulting from a single exposure to a toxin, 1-methyl-4-phenyl-1,2,3,6-tetrahydropyridine (MPTP) [160]. Surprisingly, an inverse relationship has also been found between cigarette smoking and the risk for $\mathrm{PD}$, which has been considered to provide support for an environmental cause of PD [151].

\section{Treatments for Parkinson's disease}

The current treatment of PD involves alleviation of symptoms through pharmacologic replacement of DA with L-DOPA (immediate precursor of dopamine; also referred to as Levodopa (International Nonproprietary Name)) [145,150,161]. Additionally, a peripheral DOPA-decarboxylase inhibitor is co-administered to control disabling side effects, and together these drugs effectively alleviate akinesia and rigidity in early- and middle-stage disease [150]. This combination therapy has been the gold standard for symptomatic treatment of PD for four decades [161]. Other drugs have also been developed such as dopamine receptor agonists, slow-release L-DOPA formulations, inhibitors of degrading enzymes catechol-O-methyltransferase and monoamine oxidase $\mathrm{B}$, dopamine transport blockers, anti-cholinergic drugs, and anti-glutamatergic drugs $[148,150,161]$. However, these medications do little to prevent or reverse disease progression, and efficacy declines several years after disease onset $[145,150]$. Furthermore, after long-term levodopa therapy patients frequently develop severe side effects, particularly in the form of dyskinesias $[150,161]$.

The use of neurosurgery as a therapy for PD has been revisited after originally being implemented over 50 years ago [150,161]. At that time, surgical intervention was not very reliable, and could only address tremor symptoms. Presently, neurosurgery has shown promise with the advent of modern imaging techniques, electrophysiological monitoring during surgery, improved understanding of basal ganglia circuits and disturbances caused by PD that have allowed identification of critical target sites, as well as the introduction of chronic deep-brain stimulation for functional and reversible inhibition of target areas $[148,150,161]$. Now, rather than focusing on primary symptom relief, surgical intervention has been applied for controlling levodopa-induced dyskinesias, therefore extending pharmacotherapy to advanced patients [150]. New approaches are needed for pharmacological therapies for
$\mathrm{PD}$, and while drug trials concentrate primarily on motor symptoms and complications, studies have found that quality of life is, instead, determined by other factors, including depression and dementia [148]. Another approach under investigation as a potential treatment for PD is cellular therapy by transplantation of DA-producing cells, which at present, remains predominantly experimental.

\section{Experimental animal models of Parkinson's disease}

A number of experimental models of $\mathrm{PD}$ are available, which have proven to be valuable tools in evaluating clinical approaches for symptomatic treatments. This has allowed the development of effective DA replacement therapies that are now routinely used in clinical settings, and is one of the major reasons for the advancement of PD therapies in comparison with other neurodegenerative diseases, which still lack effective symptomatic treatments [162]. Nevertheless, whilst many approaches have been taken for producing animal models of $\mathrm{PD}$, including use of a range of toxins, transgenic expression of mutant proteins involved in familial PD, and deletion of genes affecting dopaminergic neuronal development (knock-out models), there are still no accepted experimental models that closely resemble the progression and pathogenesis of PD as observed in humans [162]. Additionally, while the existing models have demonstrated utility in identifying symptomatic treatments, these models have been much less successful in discovering neuroprotective therapies [162]. For this purpose, new models may be required which more accurately portray PD pathogenesis as it affects humans [162].

Two of the most extensively studied models of $\mathrm{PD}$ are the 6-Hydroxydopamine (6-OHDA) and the MPTP toxin-based models $[149,162,163]$. Once it was found that $6-$ OHDA exhibited toxicity towards catecholaminergic neurons (dopamine and noradrenaline), it was applied in the depletion of these neurotransmitters in the forebrain and opened the way for toxin-based models of PD [149,162,164,165]. Destruction of catecholaminergic neurons is believed to occur through the selective uptake of 6-OHDA by these neurons, and autooxidation of 6-OHDA following intracellular metabolism, resulting in the simultaneous formation of several cytotoxic products [166]. The unilateral 6-OHDA-lesioned rat has become the universal standard model for assessing potential PD pharmacotherapies [149]. Typically, the neurotoxin is stereotaxically injected into the medial forebrain bundle or substantia nigra of one hemisphere, causing unilateral degeneration of the nigrostriatal pathway and depletion of striatal DA $[149,162]$. Unilateral lesioning results in a quantifiable functional asymmetry that is readily measurable by inducing rotational behavior in rats with administration of direct or indirect DA agonists, apomorphine and amphetamine, respectively [149,163,165]. Furthermore, several other deficits exist in this model that correspond with the degree of nigrostriatal loss, including abnormalities in sensorimotor performance, posture and paw usage [163,167].

Although, the 6-OHDA model is useful for testing symptomatic treatments, there exist several discrepancies between this experimental model and PD in humans. Firstly, it only reproduces a single component of the cell death process rather than the complex cascade of events that occurs in PD; secondly, there is little evidence of Lewy body formation, despite this being a characteristic pathological hallmark of PD; thirdly, the pattern of pathology and cell loss in different neural regions is not reproduced; and fourthly, 6-OHDA administration leads to acute death of dopaminergic neurons in the substantia nigra, rather than the progressive degeneration usually observed in PD [149,162,168]. Other drawbacks of this model include the need for stereotactic application of 
6-OHDA to appropriate regions of the brain, and that using rotational behavior as a measure of functional improvement is not relevant to the pathophysiology of PD symptoms [168].

The discovery that MPTP causes an irreversible and severe parkinsonian syndrome in humans that is almost indistinguishable from PD provided perhaps the greatest advance in PD experimental models, and also led to the first effective non-human primate model of PD [162]. Generally, the MPTP model is produced with systemic administration of MPTP, and a murine model is widely utilized, but, this is not as robust and reproducible a model of PD as sometimes reported [162]. The mechanism of action of MPTP involves entry of the neurotoxin into the CNS, followed by metabolism into the active form (1-methyl-4- phenylpyridinium) by astrocytes, and entry into dopaminergic neurons via the dopamine transporter, where it inhibits complex I of the mitochondrial electron transport chain $[152,169]$. Important roles for glial activation and the accompanying upregulation of inducible nitric oxide synthase in MPTP neurotoxicity have also been discovered $[152,169]$. Although, like most toxin-based PD models, the MPTP model is also divergent from PD in humans for the same reasons as the 6-OHDA model $[162,168]$. Additional drawbacks exist with the MPTP model, such as the lack of permanency of motor deficits, and tremor symptoms are not often observed [168].

\section{Cellular Replacement Therapies for Parkinson's Disease}

The primary aim of cell-based treatments for PD is to restore neuronal function by transplanting cells with DA-producing capacity into the striatum in an attempt to replace the lost nigrostriatal neurons. Ideally, the implanted cells should also reconstitute neural networks and provide physiologically-regulated feedback-controlled DA release to prevent graft-related side effects [170]. Cell transplantation therapy is believed to hold great potential for PD, due to the localized nature of this lesion, however, at present research in this area is still largely exploratory [170]. In addition, several issues concerning cell transplantation exist that have limited research progress, including scientific, technical and ethical difficulties [148]. Nonetheless, encouraging results have been reported in both animal models and human clinical trials, suggesting that further understanding of appropriate cell populations and target sites for transplantation, as well as improved surgical and technical approaches, could lead to the development of much needed neuroprotective or neurorestorative interventions for PD.

\section{Fetal neural tissue transplantation in Parkinson's disease}

A variety of cellular sources have been investigated for the potential to act as a renewable supply of transplantable dopaminergic neurons for PD, including fetal brain tissue, embryonic and adult SC populations, and xenogeneic porcine fetal nigral tissue. In preclinical studies involving neurotoxin-induced parkinsonian rodents and non-human primates, transplantation of embryonic or fetal dopaminergic neuronrich mesencephalic tissue resulted in the amelioration of at least some aspects of lesion-induced motor deficits [171-176]. Additionally, these studies revealed that grafted cells survived, produced DA, formed effective dopaminergic terminals and synapses, and re-innervated the striatum. Furthermore, graft survival and functional improvements were also reported in xenogeneic situations, with transplantation of human fetal mesencephalic tissue from 6.5-9 week old or first trimester donors into the striatum of Parkinsonian rats [177-179].

These promising findings led to the initiation of clinical trials in the late 1980s, in which fetal ventral mesencephalic tissue from aborted human fetuses were transplanted into patients with PD [180182]. The majority of the early studies were open-label, uncontrolled trials, which reported a remarkable ability of transplanted human fetal dopaminergic cells to survive and provide clinically meaningful improvement that in some cases could replace pharmacological therapies [183-192]. However, subsequent double-blind, placebocontrolled trials were unable to replicate these findings, and failed to show evidence of significant clinical benefit, with a few patients also developing dyskinesias or abnormal movements [170,193-195].

Recent clinical trial results have proven more optimistic, with most human dopaminergic neuron-containing transplants found to display functional activity for at least a decade [196-198]. Moreover, Mendez and colleagues detected the presence of graft survival in the absence of pathology for at least 14 years after transplantation [198]. Notably, other reports found that in a few long-term cases ( 11 years post-transplant), a minor proportion of surviving dopaminergic neurons showed signs of pathological changes associated with $\mathrm{PD}$, including protein aggregation and fibrillar changes suggestive of Lewy body formation $[197,199]$. The mechanism underlying this observed pathology remains unknown, and reflects the many biological and technical challenges that lie ahead in developing a cell-based therapy for PD.

\section{Neural stem cell transplantation in Parkinson's disease}

One of the limitations of using fetal neural tissue for cellular therapies is the rarity of developing dopaminergic neurons appropriate for transplantation, which are only present in 6-8 week old embryos $[195,200]$. This, together with the low post-operative survival of these cells, necessitates the sourcing of mesencephalic tissue from multiple aborted fetuses, as well as transplantation within hours of tissue harvesting [200]. To address this problem, research efforts since the early 1990s have been directed towards investigating the potential of different SC populations to act as an alternative dopaminergic cell source $[170,195]$.

At first, in vitro culture expanded human fetal neural precursor cells were employed in the 6-OHDA unilaterally lesioned Parkinsonian rat model [201-203]. These studies revealed that upon transplantation into the lesioned adult striatum, expanded neural precursors were capable of survival, migration and differentiation towards glia and neurons, including $\mathrm{TH}$-immunoreactive neurons. Although, in contrast with the large self-contained tissue masses formed by primary fetal neural tissue grafts, the expanded neural precursors formed only thin grafts containing small numbers of surviving cells, and did not migrate extensively into host tissues. Occasional TH-positive cells were detected in low numbers, with the observed expression perhaps being a transient event. In most cases, the small number of these cells was unable to elicit any functional effects, except in 2 animals that displayed partial reversal of lesion-induced rotation deficits. While the generation of some TH-positive neurons in these studies provided encouragement, it was clear that improvements were necessary for increased graft survival and dopaminergic differentiation.

Studer et al. [204] addressed these issues through in vitro culture expansion and pre-differentiation of neural precursors toward dopaminergic neurons prior to implantation. Using this procedure the yield of dopaminergic neurons was increased and partial alleviation of behavioral deficits in hemiparkinsonian rats could be achieved. However, in vitro expansion was only performed for a short period (6-8 days) and the degree of expansion was small [200]. Subsequent studies have continued to examine these issues, and have tested the use 
of NSCs from different neural regions, different expansion and predifferentiation techniques, ex vivo genetic modification of cells, and administration of trophic factors together with cell transplantation, with varying degrees of success. Common to the majority of these studies is the limited access to autologous NSCs from patients, due to the location of NSCs within the brain. Interestingly, a possible autologous cell source for PD cellular therapy has recently been described in a study showing functional improvement in the 6-OHDA rat model using SCs from rat and human olfactory mucosa [205].

\section{Embryonic stem cell transplantation in Parkinson's disease}

Another potential source of cells that have been investigated are ESCs, which also provide opportunities for the development of large quantities of therapeutically useful cells. The first demonstration of TH-positive neuronal cell derivation from ESCs was reported by Lee, et al. [206]. This study implemented a differentiation protocol that comprised of multiple induction stages, including embryoid body generation, selection of CNS SCs with a defined medium, proliferation of these cells using mitogen FGF-2, together with SHH and FGF-8, and differentiation and maturation following removal of FGF-2 and supplementation with ascorbic acid (AA). Cells obtained through this procedure were found to express CNS- and midbrain-specific genes in a pattern suggestive of progressive restriction to a mesencephalic and metencephalic CNS SC fate. Furthermore, murine ESC-derived neurons were shown to produce DA, respond to neurotransmitters, and exhibit spontaneous synaptic activity. By the end of the final stage, this system yielded $>30 \% \mathrm{TH}$-positive neurons, giving strength to the possibility of using ESCs as a reliable donor cell source for dopaminergic neuron transplantation in PD [206].

This prospect was further extended by studies investigating the in vivo transplantation potential ofESCs in the 6-OHDA hemiparkinsonian rodent model. Transplantation of low numbers of undifferentiated murine ESCs into the rat striatum resulted in spontaneous generation of dopaminergic neurons capable of gradual and sustained restoration of motor asymmetry from 5-9 weeks post-transplantation [207]. In addition, PET and functional magnetic resonance imaging scans also confirmed that the ESC-derived dopaminergic neurons had become integrated within the host brain circuitry and mediated functional improvement. Nevertheless, $20 \%$ of rats receiving grafts developed teratomas within 9 weeks at the site of transplantation[207], indicating the need for caution and removal of proliferating and non-neuronal cells prior to application of this technique in the clinic.

However, another study reported the absence of teratoma formation and proliferative marker $\mathrm{Ki}-67$, when pre-differentiated NR4A2-transfected ESCs were grafted into the striatum of 6-OHDA lesioned rats [208]. Graft analysis revealed the presence of THpositive cells that possessed complex cellular morphologies, with the immunoreactive cell bodies restricted to the graft region, whereas TH-positive cell processes extended into the parenchyma of the host striatum up to $2 \mathrm{~mm}$ away from the graft site. Additionally, these cells were found to release DA, form functional synaptic connections and modulate spontaneous and pharmacologically-induced behaviours, strongly supporting the capability of ESC-derived neurons to survive and function after intrastriatal grafting [208]. Following these findings, other studies have continued to improve these procedures by examining different methods of pre-differentiation (cytokines, inductive factors, genetic modification, co-culture systems, and combinations of these), selection and enrichment of dopaminergic neuron populations, and combining trophic factor administration with transplantation.

\section{Patient-specific cellular transplantation in Parkinson's disease}

Recent advances in the understanding of pluripotent SC biology have extended this work to include the possibility of patient-specific dopaminergic neuron replacement therapies. Therapeutic cloning strategies have been utilized to generate nuclear transfer ESCs, using donor fibroblasts obtained from individual 6-OHDA lesioned hemiparkinsonian mice [209]. The genetically matched ESCs were then differentiated into midbrain dopaminergic neurons and transplanted back into the original donor mouse. Significantly, this study found enhanced graft survival and amelioration of parkinsonian behaviour with autologous grafts, in comparison with allogeneic grafts, which appeared to be related to decreased graft immunogenicity [209].

In another study by Jaenisch and colleagues [210], the need for nuclear transfer techniques was circumvented through the use of induced pluripotent stem (iPS) cells [211,212]. Murine iPS cells were successfully differentiated into dopaminergic neurons of midbrain character through application of regional patterning factors $(\mathrm{SHH}$ and FGF-8) to FGF-2 responsive, iPS cell-derived neural precursor cells. Intrastriatal transplantation of these cells into the 6-OHDA unilaterally lesioned rat model of PD resulted in marked improvement in rotational behaviour at 4 weeks post-grafting. Attempts were also made to minimize the risk of teratoma formation by employing fluorescence-activated cell sorting (FACS) to remove contaminating pluripotent cells (SSEA1-positive fraction) from the cell suspension prior to transplantation [210].

\section{Challenges in cellular replacement therapies for Parkinson's disease}

Many important biological, technical, and surgical hurdles and challenges need to be addressed before cellular replacement therapy for PD patients can be implemented in the clinic. Currently, detailed knowledge is still required concerning critical issues, such as: 1) the appropriate neuronal (and perhaps also glial) cell type for transplantation, including the cellular and biochemical characteristics necessary in the donor cell population; 2) the correct anatomical location for cell administration; 3) suitable selection criteria for identifying patients most likely to respond to cellular replacement therapy, which may be influenced by the stage of the disease and responsiveness to levodopa; 4) effective parameters for cell preparation and delivery to obtain optimal graft survival, including the optimal volume, dosage and format of cells; 5) mechanisms for limiting host immunological responses to donor cells; and 6) connectivity variables for functional reconstitution of neurocircuitry [170].

Another crucial challenge for clinical application is the optimization of graft function, whilst preventing graft-related side effects, since midbrain dopaminergic neurons are highly specialized cell types that must be capable of physiologically appropriate DA release and establishment of specific short- and long-distance connections within a complex cellular network [170]. Additionally, investigation of cellular transplantation therapies must take into account the rate of cellular maturation when progenitor cell populations are used, since this is donor dependent and currently available data indicates that long-term clinical evaluation periods may be necessary [170]. Production of clinical grade, individual, patient-specific cell lines also presents a considerable logistical challenge [195]. It must also be remembered that the pathological changes present in PD are not restricted to dopaminergic neurons alone, with degeneration occurring 
in other neural regions [195]. However, while gaps exist in our current knowledge, renewed hope is provided through the major research efforts directed towards understanding and developing novel cellular therapies for PD.

\section{MSC-Based Cellular Therapies for Parkinson's Disease}

A number of investigations have been performed to determine the potential of MSCs to differentiate into functional DA-producing neuronal-like cells, and to examine the capability of MSC grafts to re-innervate the striatum and ameliorate behavioural deficits in animal models of PD. To date, these studies have exhibited varying degrees of success, ranging from the generation of TH-positive cells, to observations of electrophysiological activity and DA secretion, to significant improvements in pharmacologically-induced rotational behaviour in hemiparkinsonian rodent models. Although, amongst the different studies a diverse array of methodologies have been employed and variations exist in the cell types obtained, which together have caused difficulty in the evaluation and comparison of experimental outcomes. Nevertheless, the promising results that have been reported provide much encouragement for the prospect of developing a MSCbased cellular therapy for PD.

\section{Undifferentiated MSCs express dopaminergic neuronal markers}

Recent findings from our laboratory and others, have described the expression of key markers of the neuro-dopaminergic system by rat and human MSCs prior to commencement of neuronal differentiation procedures. These markers include TH, NR4A2, PITX3, EN1, aldehyde dehydrogenase 1, aromatic L-amino acid decarboxylase, catechol-omethyltransferase, GTP cyclohydrolase-1, OTX-1, SHH receptor components (patched and smoothened), and GDNF family receptor alpha $1[48,213,214]$. Expression of these dopaminergic neuronal markers demands that caution be taken in the interpretation of hMSC neural differentiation, particularly through examination of neural markers prior to differentiation as well as post-differentiation. However, these observations also provide support for the dopaminergic neuronal differentiation capacity of hMSCs [215]. Furthermore, the constitutive NR4A2 expression present in hMSCs suggests that these cells may be viable candidates for cellular replacement therapies for $\mathrm{PD}$, particularly since transfection of ESCs with NR4A2 was considered to be crucial for the successful generation of ESC-derived dopaminergic neurons [208]. This study demonstrated that stable transfection of murine ESCs with NR4A2 in conjunction with a five-stage dopaminergic neuronal differentiation method allowed the generation of $\mathrm{TH}$-expressing neurons with electrophysiological activity and the ability to promote significant behavioural recovery in transplanted Parkinsonian rats.

\section{Dopaminergic neuronal differentiation of MSCs and transplantation in parkinsonian models}

Similar methods have been investigated for dopaminergic neuronal differentiation of MSCs as have been utilized in general MSC neuronal differentiation, but with the inclusion of factors more specific to midbrain dopaminergic neuron development. At present, there are a limited number of reports describing dopaminergic neuronal differentiation of MSCs from rodents $[24,62,81,216,217]$ and humans $[25,74,81,101,103,214,218-220]$. The majority of these studies employed the addition of extrinsic factors to cell cultures, such as cytokines and small molecules; however, the effects of gene transfection, conditioned medium and co-culturing, as well as combinations of these methods were also investigated. These studies are summarized in Table 1.
The initial report by Jiang and colleagues [24] described a multistage differentiation strategy capable of generating midbrain neuronallike cells from the MAPC subset of murine MSCs. The first stage consisted of supplementation with FGF-2 (7 days), followed by a combination of FGF-8 and SHH (7 days), then BDNF (7 days), and finally co-culture with fetal brain astrocytes (5-12 days). Phenotypic and electrophysiological characteristics similar to midbrain neurons were obtained, with approximately $25 \%$ efficiency of dopaminergic neuron generation. Co-culturing with astrocytes also resulted in 80$100 \%$ of cells acquiring functional voltage-gated sodium channels. In addition, activation of transcription factors known to be involved in neuroectodermal development, such as SOX1, OTX2, OTX1, PAX2, $P A X 5$ and NR4A2, were detected in a similar developmental pattern as described for NSC and ESC dopaminergic differentiation [24]. However, a number of caveats are associated with this approach, including lack of specificity for dopaminergic neuron production, since serotonergic ( 25\%) and GABA-ergic ( 50\%) neurons were also produced, and as a consequence of this, requirement for selection of desired dopaminergic cells. Additionally, astrocyte-conditioned medium or cytokines alone were unable to provide appropriate differentiation signals, therefore, astrocyte co-culture is necessary, which impedes clinical translation. This study was also conducted using murine cells, and whether the same results can be obtained in humans must be confirmed.

The next key study demonstrating production of dopaminergic neuronal-like cells from MSCs employed transfection of the NICD gene and administration of trophic factors FGF-2 and CNTF with forskolin, followed by addition of GDNF [81]. Importantly, it was shown that this approach could generate TH-positive cells with $41 \%$ efficiency, which was the highest reported rate at the time, and the cells obtained also displayed in vitro and in vivo functional properties of neurons, with little glial differentiation. Delayed rectifier potassium currents were recorded after treatment with FGF-2, CNTF and forskolin, whereas further administration of BDNF and NGF was necessary for voltagegated fast sodium currents and action potentials. Treatment with GDNF elevated the expression of transcription factors NR4A2, LMX1B, EN1 and PITX 3 , and also resulted in in vitro DA release in response to high $\mathrm{K}^{+}$depolarizing stimuli. Significant improvements were also detected in hemiparkinsonian rats, in terms of apomorphine-induced rotational behaviour and non-pharmacological assessments (step adjustment and paw-reaching tests). Additionally, the authors confirmed that similar results could be obtained when using rat or human MSCs [81]. However, this study was not without limitations. The use of gene transfection may be problematic for application in the clinic, although it was noted that this could be avoided through induction with a JAK/ STAT inhibitor [81]. Also, while neural trophic factors were employed, those typical of midbrain dopaminergic neuronal specification were not included, suggesting that the observed differentiation may be divergent from that occurring in normal development.

Application of extrinsic factors alone has also resulted in the induction of MSCs toward a dopaminergic neuronal phenotype $[25,62,74,103,216,217,219,220]$. An NSC- like population was obtained from hMSCs through the formation of neurosphere-like structures in low-attachment culture flasks in the presence of serum-free medium containing EGF and FGF-2 [25]. The majority of the neuroprogenitorlike cells obtained upregulated expression of NES protein to high levels, while mesodermal fibronectin protein was downregulated. Quantitative PCR analysis showed decreases in SOX1, POU5F1, and neurotrophic tyrosine kinase receptor type 1 , whereas neuroectodermal 
Citation: Khoo MLM, Tao H, Ma DDF (2011) Mesenchymal Stem Cell-Based Therapies for Parkinson's Disease: Progress, Controversies and Lessons for the Future. J Stem Cell Res Ther S2:005. doi:10.4172/2157-7633.S2-005

Page 13 of 24

\begin{tabular}{|c|c|c|c|}
\hline Differentiation Method & Cell Type & Results (In vitro/In vivo) & References \\
\hline $\begin{array}{l}\text { Multi-stage method: } \\
\text { 1) FGF-2 (7d) } \\
\text { 2) FGF-8, SHH (7d) } \\
\text { 3) BDNF (7d) } \\
\text { 4) Astrocyte co-culture (5-12d) }\end{array}$ & Murine MAPC & $\begin{array}{l}25 \% \text { efficiency of dopaminergic neuron } \\
\text { generation (IF); electrophysiological } \\
\text { characteristics similar to midbrain } \\
\text { neurons }\end{array}$ & Jiang et al. [24] \\
\hline $\begin{array}{l}\text { NICD transfection, FGF-2+CNTF+ FBS } \\
\text { +forskolin (5d), GDNF or BDNF+NGF } \\
\text { (7-11d) }\end{array}$ & Human and rat MSCs & $\begin{array}{l}41 \% \text { TH-positive (IF); } \\
\text { electrophysiological properties; DA } \\
\text { release after depolarization; functional } \\
\text { improvement in hemiparkinsonian rats }\end{array}$ & Dezawa et al. [81] \\
\hline $\begin{array}{l}\text { Neurosphere formation with EGF+FGF-2 } \\
(2-10 \text { weeks), BDNF }(10-14 d)\end{array}$ & Human MSCs & $\begin{array}{l}\text { 11\% TH-positive (IF); DA release after } \\
\text { depolarization; loss of osteogenic } \\
\text { differentiation capacity }\end{array}$ & Hermann et al. [25] \\
\hline $\begin{array}{l}\text { Neurosphere formation with } \\
\text { IBMX+forskolin+ TPA (3hrs), dbcAMP } \\
\text { (7d) }\end{array}$ & Human MSCs & $\begin{array}{l}15 \% \text { of } \beta \text { tubulin III-positive cells also } \\
\text { TH-positive (IF); lack of graft survival } \\
\text { and differentiation in PD model }\end{array}$ & Suon et al. [74] \\
\hline $\begin{array}{l}\text { IBMX (2d), GDNF+ IL-1 } 1 \beta+\text { mesencephalic } \\
\text { glial-conditioned med-ium+flash-frozen } \\
\text { mesencephalic cell fragments (7-15d) }\end{array}$ & Rat MSCs & 35\% TH-positive (IF) & Guo et al. [62] \\
\hline $\begin{array}{l}\text { Expansion (10\% FBS+ DMEM; } 3 d) \text {, } \\
\text { neuron-conditioned medium alone (6- } \\
9 \mathrm{~d}), \text { SHH+ FGF-8+neuron-conditioned } \\
\text { medium (3-12d) }\end{array}$ & $\begin{array}{l}\text { Human MSCs from Wharton's jelly of } \\
\text { umbilical cord }\end{array}$ & $\begin{array}{l}\text { 12.7\% TH-positive (IF); DA secretion; } \\
\text { partial correction of amphetamine- } \\
\text { evoked rotational behavior }\end{array}$ & Fu et al. [218] \\
\hline $\mathrm{CoCl}_{2}+\mathrm{Y}-27632(72 \mathrm{hr})$ & Murine MSCs & $\begin{array}{l}\text { TH expression; neurotransmitter } \\
\text { responsiveness: glutamate }(42 \%) \text {, DA } \\
(76 \%)\end{array}$ & Pacary et al. [216] \\
\hline SHH+FGF-8+FGF-2 (12d) & Human MSCs & $\begin{array}{l}67 \% \text { TH-positive (IF); synthesize and } \\
\text { constitutively secrete DA }\end{array}$ & Trzaska et al. [101] \\
\hline $\begin{array}{l}\text { FGF-2+EGF (48hr), BHA+dbcAMP+IBMX } \\
\text { +RA+GDNF (96hr) }\end{array}$ & Human MSCs & $\begin{array}{l}\text { TH protein expression; DA secretion; } \\
31 \% \text { TH-positive (flow cytometry) }\end{array}$ & Kan et al. [103] \\
\hline $\begin{array}{l}\text { FGF-2+EGF }(48-72 h r) \\
\text { dbcAMP+IBMX+AA+ } \\
\text { GDNF+ TGF3+RA) (7d) }\end{array}$ & Human MSCs & $\begin{array}{l}30 \% \text { TH-positive (flow cytometry); DA } \\
\text { secretion in response to depolarization }\end{array}$ & Barzilay et al. [219] \\
\hline $\begin{array}{l}\text { Multi-stage: } \\
\text { 1) FGF-2 (7d) } \\
\text { 2) SHH+FGF-8 (7d) } \\
\text { 3) BDNF (7d) }\end{array}$ & Rat MSCs & $\begin{array}{l}60 \% \beta \text { tubulin III-positive; none TH- } \\
\text { positive; functional improvement in } \\
\text { hemiparkinsonian rats, but in both } \\
\text { control and neuronal-like MSCs }\end{array}$ & Bouchez et al. [208] \\
\hline $\begin{array}{l}\text { FGF-2+GDNF+10\% fetal calf serum } \\
(2 w k)\end{array}$ & Human MSCs (PD-derived) & $\begin{array}{l}30 \% \text { TH-positive (flow cytometry); DA } \\
\text { release after depolarization }\end{array}$ & Zhang et al. [220] \\
\hline $\begin{array}{l}\text { Multi-stage: } \\
\text { 1) FGF-2+EGF (7d) } \\
\text { 2) } S H H+F G F-8+A A(7 d) \\
\text { 3) GDNF+AA (7d) }\end{array}$ & Human MSCs & $\begin{array}{l}60-80 \% \text { tubulin III-positive; none TH- } \\
\text { positive; transient survival of Stage } 1 \\
\text { cells in lesioned hemisphere; microglial } \\
\text { and astroglial accumulation around graft }\end{array}$ & Khoo et al. [214] \\
\hline
\end{tabular}

Table 1: In Vitro Dopaminergic Neuronal Differentiation of MSCs.

transcripts OTX1, NEUROD1, NEUROG2, musashi and NES were acquired with neurosphere formation. Further differentiation was achieved using BDNF for neuronal differentiation (42\% $\beta$ tubulin III positive), or PDGF for glial differentiation (45\% GFAP-positive and 27\% GALC-positive). Interestingly, with this general neuronal differentiation procedure, $11 \%$ of cells expressed $\mathrm{TH}$ and were capable of releasing DA in response to membrane depolarization in vitro. In addition, osteogenic differentiation capacity was lost after induction into neuroprogenitor-like cells [25]. However, the electrophysiological function of neuronal-like cells could not be examined due to technical constraints, and further assessment of function through in vivo transplantation is required. This system does not appear capable of generating mature neuronal cells, although the authors suggested that immature cells are more suitable for transplantation, since fully differentiated mature neural cells poorly survive detachment and transplantation [25]. Additionally, MSC dopaminergic neuronal differentiation occurred at a low rate, although even this is surprising given the lack of specific dopaminergic inductive cues.

Neural progenitor-like sphere formation has also been utilized prior to dopaminergic neuronal differentiation by plating spheres on a poly-ornithine/laminin-coated surface in serum-free medium containing IBMX, forskolin and TPA for 3 hours, followed by dbcAMP for 7 days [74]. Down-regulation of mesenchymal genes was observed with concomitant up-regulation of neural-associated genes. Additionally, 
$15 \%$ of $\beta$ tubulin III-positive cells also expressed TH. Surprisingly, all of the cells expressed GABA, including those found to be TH-positive. Intrastriatal transplantation of MSC-derived spheres in 6-OHDA unilaterally lesioned rats resulted in short-term graft survival, however, no further dopaminergic differentiation could be observed, and instead only GABA-positive cells were detected. The lack of survival of transplanted hMSCs, despite administration of cyclosporine A, reveals a potential limitation in this method of assessment of hMSC in vivo function.

Yet another differentiation approach was taken by Guo, et al. [62], which yielded a rate of 35\% TH-positive cells from rat MSCs, after exposure to IBMX for 2 days, followed by application of GDNF, IL-1 $\beta$, mesencephalic glial cell-conditioned medium, and flashfrozen mesencephalic cellular fragments for 7-15 days. However, examination of DA secretion and excitability of the resulting cells was not performed, and assessment of this system using hMSCs is yet to be done. In addition, treatment with glial-conditioned medium and membrane fragments is unsuitable for use in clinical settings.

The remaining studies employed similar procedures including: multiple-stage application of cytokines FGF-2 (1 week), SHH+FGF-8 (1 week) followed by BDNF (1 week) [217]; treatment with FGF-2/ EGF for 48 hours as step 1, then application of BHA, dbcAMP, IBMX, RA and GDNF for 96 hours as step 2 [103], and a later study by the same group found improved TH expression with addition of dbcAMP, IBMX and AA with BDNF alone or GDNF/RA/TGF- $\beta 3$ in the second step [219]; application of $\mathrm{CoCl}_{2}$ and Y-27632, to presumably cause hypoxia-inducible factor 1 activation and Rho kinase inhibition [216]; and treatment with cytokines FGF- 2 and GDNF, and 10\% fetal calf serum, for 2 weeks [220]. A varying degree of success was achieved, including depolarization-induced secretion of DA [103,219,220], and reduction of behavioral deficits in a Parkinsonian rat model [217]. Furthermore, it was demonstrated for the first time that hMSCs isolated from PD patients could be induced toward a DA-secreting neuronal phenotype, with expression of $\mathrm{TH}$ protein in approximately $30 \%$ of cells [220].

MSCs isolated from Wharton's jelly of human umbilical cord were also employed in a multi-stage differentiation method consisting of expansion in 10\% FBS-DMEM for stage 1, neuronal differentiation through incubation with neuron-conditioned medium in stage 2 , and induction of a dopaminergic neuronal phenotype with application of neuron-conditioned medium, SHH and FGF-8 [218]. TH-positive neurons were generated with approximately $12.7 \%$ efficiency, and DA secretion into the culture medium was detectable. In addition, functional effects were observed in vivo following transplantation into the striatum of hemiparkinsonian rats, as seen by partial correction of amphetamine-evoked rotational behavior. The primary caveat of this work was the low efficiency of dopaminergic neuronal differentiation, which may have contributed to the incomplete behavioral recovery. Electrophysiological characteristics of the resulting cell population were also not examined, and it should be noted that umbilical cordderived MSCs have been reported to possess different properties than adult BM-derived MSCs [221].

A single-step cytokine-based procedure for inducing a dopaminergic neuronal phenotype from hMSCs was reported by Trzaska and colleagues [101]. This method utilized a cocktail of cytokines (SHH, FGF-8, and FGF-2), and generated promising results including the highest reported efficiency of TH-positive cell production ( $67 \%)$, expression of dopaminergic-specific genes, synthesis and secretion of
DA, and the presence of electrophysiological properties comparable with immature neurons. However, despite detection of DA release in vitro, this was not found to occur in response to depolarization, and instead DA was found to be constitutively released into the culture medium. Although up-regulation of dopaminergic-specific markers was demonstrated, examination of mesodermal and MSC markers was not conducted, and in order to show clear dopaminergic neuronal differentiation, one would expect to observe concomitant downregulation of markers of MSCs and the mesodermal lineage.

Our laboratory has also endeavored to induce a dopaminergic phenotype through sequential application of growth factors important in midbrain dopaminergic neuronal development [214]. This procedure (MultiDA method) consisted of initial application of FGF2 and EGF to prime hMSCs toward a neural fate, followed by $\mathrm{SHH}$, FGF-8 and ascorbic acid to initiate midbrain specification, and lastly GDNF and ascorbic acid to induce differentiation and maturation towards a dopaminergic neuronal phenotype. Since a range of methods have been reported and no consensus exists on an optimal method, we also conducted a comparison of published methods [26,101]. Despite the different procedures employed, all three methods were effective to a similar extent and were only capable of generating immature neuronal-like cells. Interestingly, slightly different responses were elicited in hMSCs by the three methods, and the first stage of the MultiDA method was unique in the spontaneous formation of neurosphere-like structures, together with the greatest upregulation of NES and NR4A2. Transplantation of neural-primed hMSCs yielded transient survival in the lesioned hemisphere of immunosuppressed Parkinsonian rats, which may have been due to the accumulation of microglia and astrocytes around graft sites, suggestive of the presence of an inflammatory response. We found that the growth factor-based methods were successful in driving hMSCs toward an early neuronal fate; however cells continued expressing mesodermal and pluripotency markers, suggesting the need for further neuronal differentiation. Further experiments are warranted for investigating whether the electrophysiological properties of these neuronal-like cells resemble those of immature neurons.

The above studies that examined the in vivo functional potential of MSC-derived dopaminergic neuron-like cells have often found behavioral improvement with transplantation of these cells over that of control undifferentiated MSCs. However, other studies have reported survival, migration, generation of TH-positive cells and functional improvement with transplantation of undifferentiated MSCs [222,223] $\mathrm{Li}$ and colleagues [222] performed the initial study investigating intrastriatal MSC transplantation in a murine MPTP-induced bilateral model of PD. Behavioral recovery was analyzed using the rotarod test, with results showing that mice with a MSC graft exhibited prolonged duration on the rotarod at day 35 , when compared with control sham grafted mice. Additionally, MSCs were found to survive within graft sites for at least 4 weeks, and a small proportion of scattered MSCs were TH-immunoreactive. However, the authors hypothesized that the therapeutic benefits most likely originated from MSC secretion of growth factors capable of promoting survival and plasticity within the damaged brain, since improvement was observed rapidly and few MSCs were present in the target tissue [222]. Hellmann, et al. [223] also transplanted undifferentiated MSCs into parkinsonian rodents (6-OHDA unilaterally lesioned), but for the purposes of assessing MSC survival, migration and differentiation. It was found that MSCs exhibited higher survival in the lesioned hemisphere in comparison with the unlesioned side. In addition, MSC transplantation into the striatum 
contralateral to the lesion resulted in migration of MSCs through the corpus callosum into the striatum, thalamic nuclei and substantia nigra of the 6-OHDA lesioned hemisphere [223]. These studies suggest that the therapeutic benefits observed following MSC transplantation in rodent PD models may be conferred through mechanisms other than cellular replacement and DA production.

\section{Optimization of MSC dopaminergic neuronal differentiation}

The cytokine induction methods employed by our laboratory were only successful in driving hMSCs toward an early neuronal fate, with cells continuing to express neuronal progenitor marker NES and pluripotency markers POU5F1 and NANOG [214]. Furthermore, the persistence of mesodermal and glial markers, together with the pluripotency markers, suggests that additional differentiation signals are required for attaining proper neuronal differentiation and maturation. A comparative study conducted by Hermann and colleagues [215] also found continued expression of mesodermal marker fibronectin in certain neuronal differentiation methods, including the initial methods reported for cytokine-based [18] and chemical-based systems [19]. Examination of mesodermal lineage markers was not performed in these initial reports, therefore, our findings and those of Hermann and colleagues highlight the importance of showing concomitant down-regulation of mesodermal and MSC markers with neuronal differentiation.

In addition, these findings suggest that further differentiation signals or factors may be required for the in vitro neural differentiation of MSCs, particularly since a complex milieu of cytokines and signalling molecules are believed to be present in neural development in vivo. A number of potential factors have been identified to provide advantages for the neuronal and dopaminergic neuronal differentiation of MSCs. One such factor involves co-culturing MSCs together with neural support cells, such as astrocytes, which may function through direct cell-cell interactions, trophic factor production, or removal of glutamate from the culture environment [24]. Support for this approach has been shown in ESC and astrocyte co-culture systems, in which the type of neurons obtained were found to be dependent upon the regional origin of the astrocytes, with mesencephalic astrocytes strongly potentiating dopaminergic neurogenesis [224]. Another approach similar to the coculturing method is the supplementation of cultures with conditioned medium from neural support cells [64].

Recently, studies have also described improved MSC neuronal differentiation through the addition of fatty acids, such as docosahexaenoic acid and arachidonic acid [225], and inflammatory mediator IL-1a [100,226]; whilst, still others have suggested that beneficial effects could be produced through additional supplementation with RA, BDNF and/or NGF [101], or through the optimization of culture surface nanotopography [227]. However, while research efforts are continuing to reveal new insights into the induction of a dopaminergic phenotype from MSCs, further improvements and optimization of established techniques is still very much desired.

Aside from the improvement and optimization of culture components, the time required for in vitro dopaminergic neuronal differentiation requires careful consideration, as it may differ between species and may also differ to that required for other neuronal cell types. In an earlier study, Bjorklund and colleagues transplanted ESCs into the 6-OHDA unilaterally-lesioned Parkinsonian rat and demonstrated that the time course of behavioral recovery corresponded with the developmental rate (i.e. length of gestational period) of the donor species [207]. Thus, if dopaminergic differentiation of hMSCs does indeed mimic that which occurs during gestation, then it would be expected that longer periods are required for the differentiation of human cells than for rodent cells. Evidence supporting this has been shown in a meta-analysis of studies which found that behavioral recovery in Parkinsonian rats occurred approximately 5 weeks after mouse fetal ventral mesencephalon transplantation, while for the equivalent human cells, recovery only occurred after approximately 20 weeks [228]. Longer periods of in vitro hMSC differentiation may therefore be required, particularly since most protocols, including our own, have only been conducted over several weeks, which is considerably shorter than the 20 week period reported for in vivo behavioral recovery using human fetal cells. However, it should be noted that neural differentiation of hMSCs may be divergent from that occurring in normal physiological development, particularly since undifferentiated hMSCs have been shown to constitutively express some neural markers.

\section{Potential mechanisms of functional improvement following MSC transplantation}

The majority of published reports in this field have demonstrated some level of MSC- induced restoration of neurodegeneration in Parkinsonian animal models, whether it be renewed presence of immunoreactivity to dopaminergic markers within the lesioned hemisphere or functional improvement in behavioral asymmetry. Initially it was believed that neurological recovery occurred as a result of conversion of MSCs to a neural phenotype and integration into host circuitry, although more recently it has been suggested that recovery may instead be related to the secretion of trophic factors by MSCs, or interaction of MSCs with host cells $[20,21,54]$. An increasing number of studies have now described the ability of MSCs to promote tissue repair and functional improvement, despite little evidence of differentiation and only low or transient levels of in vivo engraftment $[37,38]$. These studies have suggested that MSCs may not repair tissues solely through differentiation and replacement of lost cells, but may possess a more prominent role in the secretion of factors with the ability to alter the host tissue microenvironment.

A neurotrophic response in host cells following intracerebral hMSC transplantation has been reported in a number of recent studies. Stimulation of proliferation, migration and differentiation of endogenous NSCs into neural precursors and mature cells was attributed to the secretion of NGF, VEGF, CNTF, FGF-2 and other chemokines by hMSCs [229]. It was suggested that these secreted factors acted directly on NSCs, or may have activated astrocytes that then produced the increase in neurogenesis. Improved neurologic function in an experimental model of transient forebrain ischemia was reported to occur through hMSC expression of anti-immune, antiinflammatory and anti-apoptotic-related factors and establishment of a Th2-immune bias through alternative activation of microglia and/ or macrophages by hMSCs [230]. Equivalent behavioral improvement was also observed following intrastriatal transplantation of both undifferentiated and partially neuronal-differentiated MSCs in a hemiparkinsonian rodent model [217]. Recovery occurred rapidly (within 1 week post-transplantation) and was maintained over the 6 week study period. Detection of BDNF, GDNF, FGF-2 and FGF-8 expression in vitro by undifferentiated and neuronal-differentiated MSCs, suggested that neurotrophic factor secretion could be the mechanism behind recovery [217].

The majority of recently published studies have concentrated on 
the growth factor secretory effects of MSCs in Parkinsonian rodents in vivo [231-233], or in neural co-culture systems in vitro [231,233,234]. BDNF, GDNF and FGF-2 have been found to be released by murine MSCs into culture media, and treatment of embryonic dopaminergic neurons with conditioned medium prior to transplantation yielded significantly enhanced graft survival and more rapid behavioral recovery of hemiparkinsonian rats [231]. A different strategy has also been employed in which hMSCs were directed toward an astrocytelike, neurotrophic factor-secreting phenotype [232,233]. These cells were capable of eliciting behavioral improvement, enhanced striatal DA levels, and increased $\mathrm{TH}$ immunoreactivity after intrastriatal transplantation. Interestingly, a different 6-OHDA hemiparkinsonian model was used, comprising a partial lesion with residual surviving DA terminals, which was chosen as the authors were interested in examining the protection-restoration effect of trophic factor-secreting MSCs. Furthermore, neurotrophic factor-secreting cells were not expected to be beneficial in complete lesion models, which would only show improvement with dopaminergic cell replacement [232].

In vitro effects of trophic factor secretion by MSCs have also been described, with findings of increased expression of TH and DA by ventral mesencephalic cells co-cultured with undifferentiated rat MSCs [234]. Treatment with MSC-conditioned medium also increased the survival of embryonic mesencephalic dopaminergic neurons in in vitro neuronal injury models of serum deprivation and exposure to 6-OHDA [231]. Furthermore, marked protection was demonstrated when conditioned medium from astrocyte-like, neurotrophic factor-secreting MSCs or undifferentiated MSCs were applied to neuroblastoma cell line, SH-SY5Y, one hour prior to exposure to neurotoxin 6-OHDA [233].

Together these studies provide support for alternative mechanisms by which MSCs may effect functional improvement in Parkinsonian models. Further evaluation of both the neuroprotective and cell regenerative/replacement properties of MSCs will be required in order to harness these effectively in cellular therapies for PD and other neurological diseases.

\section{Activation of innate immune response with intracerebral MSC transplantation}

Once considered as having the unique ability to suppress immune responses both in vitro and in vivo, MSCs are now recognised to possess immunomodulatory properties with the capacity to suppress and/or activate immune responses [104,105]. In addition, while the brain has been traditionally viewed as an immunologically privileged organ, evidence suggesting otherwise is now apparent and reveals routine and effective immunological surveillance of the CNS [235]. Consequently, transplanted cells and tissues are exposed to host immunological responses, particularly since the transplantation procedure elicits inflammatory processes due to surgical trauma $[236,237]$. Contrary to earlier findings, recent evidence also suggests the lack of MSC survival following intracerebral transplantation into normal or hemiparkinsonian rodents [74,214,233,238,239], raising further questions concerning the ability of MSCs to engraft and mature after transplantation into the CNS.

Coyne and colleagues demonstrated that transplantation of MSCs into the intact adult rat hippocampus or striatum elicited an immediate inflammatory response involving massive infiltration of activated microglia/macrophages and astrocytes in the presence of cyclosporine- mediated immunosuppression. This led to the rapid rejection of hMSC grafts with near complete rejection by 7 days, a much briefer period than rejection through adaptive immune responses, which generally commence 10-14 days post-transplantation [238]. The inflammatory response was ascribed to the mechanical trauma produced by intracerebral transplantation. Subsequently, robust cellular immune responses (MHC class I- and class II- expressing cells and CD4+ and CD8+ lymphocytes) were also detected following injection of undifferentiated rat MSCs into the striatum of allogeneic hemiparkinsonian recipients [239]. However, despite the presence of a marked immune response, some grafted MSCs were still detectable at 22-24 days post-transplantation; although MSC administration was not found to prevent behavioral deficits or DA depletion, and MSCs did not acquire the ability to synthesize TH [239].

These findings are in accordance with the current understanding of the role of microglia/macrophages in orchestrating the inflammatory response of CNS innate immunity [240,241]. Previous studies reported that mechanical injury to the brain provoked rapid and focal microglial activation to shield the injured area, with possible immediate phagocytic engulfment and removal of damaged tissue $[242,243]$. Microglia-mediated inflammation has also been associated with astrogliosis [244,245], and microglia have been shown to produce pro-inflammatory cytokine IL-1, which is capable of inducing astrogliosis [245]. In addition, our observations of the pattern of microglial and astrocytic distribution [214] bore resemblance to the pattern of microglial and astroglial reactions to inflammatory lesions in experimental autoimmune encephalomyelitis [244]. This pattern consisted of (1) early response of microglia to inflammatory lesions; (2) proliferation of microglia close to lesions, with astrocytes encasing the lesions; and (3) formation of micro-astroglial scars at later stages that were composed of residual inflammatory cell aggregates and dense microglial and astrocytic gliosis [244]. Additional evidence for the induction of a microglial-mediated innate inflammatory response with SC transplantation was found in a recent study examining transplantation of Müller SCs into an experimental model of retinal degeneration [246]. Extensive microglial accumulation was found in this study, in association with poor migration, integration and survival of Müller SCs [246].

Support for the rejection of hMSC transplants by an inflammatory response is found in another study examining the early cellular responses mediating rejection of xenogeneic porcine endothelial cells and fetal neurons transplanted into the rat striatum [247]. Surprisingly, rapid rejection of endothelial cell grafts within 11 days through an inflammatory response mediated by microglia/macrophages was found, whereas rejection of fetal mesencephalic neurons occurred after 3 weeks and was typical of an adaptive immune response involving $\mathrm{T}$ cells. The differences in rejection kinetics were thought to arise from the intrinsic characteristics of the xenogeneic donor cells, such as differences in MHC-I surface expression and production of proinflammatory cytokines. These findings also indicate the possibility that transplantation of non-neural cell types into neural environments elicits an immunological response distinct to that resulting from transplantation of neural cell types. In addition, since MSCs are known to secrete a wide variety of growth factors, including GM-CSF and others that support granulocyte and macrophage proliferation and maturation [248,249], Coyne and colleagues commented that the production of these factors by MSCs post-transplantation could augment post-operative inflammation, as well as aid graft destruction [238]. Further to this, GM-CSF has been described to be a potent 
mitogen for microglia, with the ability to induce reactive microglia capable of scavenging and removal of damaged tissue [245].

Despite implementation of cyclosporine immunosuppression in these studies, MSC graft rejection still occurred. Czech, et al. have also found that cyclosporine administration could not prevent or delay the rejection of xenogeneic bovine endothelial cells grafted into the rat CNS [250]. Since cyclosporine treatment acts primarily to inhibit $\mathrm{T}$ lymphocyte-mediated immunity [251,252], these findings indicate the involvement of other arms of the immune system, such as innate immunity, in MSC graft rejection. In addition, cyclosporine treatment for neural xenotransplantation has been reported to be suboptimal $[253,254]$. Furthermore, complement factors, immunoglobulins and macrophages may be involved in immune responses against discordant xenografts, and these are not affected in a crucial way by cyclosporine treatment [255-257].

Administration of further immunosuppression may therefore be required for improved MSC graft survival. Enhanced microglial suppression was employed for Müller SC transplantation into degenerated retina through application of oral cyclosporine A, azathioprine, prednisolone, and indomethacin [246]. This immunosuppressive regimen yielded decreased microglial accumulation and increased survival of Müller SCs. Other studies investigating xenograft survival in the CNS have found promising outcomes through the use of triple drug therapy (cyclosporine, methylprednisolone, azathioprine), complete complement blockade, and absence of an induced primate anti-mouse antibody response [258]; tacrolimus or cyclosporine treatment with additional inductive treatment using prednisolone or mycophenolate mofetil [259]; or local immunosuppression by co-transplantation of liposomal tacrolimus [260].

Another potential factor affecting neuronal-primed hMSC engraftment in vivo is the immunogenicity of hMSCs following in vitro differentiation. At present, the majority of studies have examined the immunomodulatory properties of MSCs in the undifferentiated state, and little is known of whether this is affected by in vitro differentiation. Recently, in vitro chondrogenic differentiation has been reported to increase the immunogenicity of rat MSCs, resulting in the stimulation and maturation of human DCs, possibly due to MSC up-regulation of costimulatory B7 molecules after chondrogenic differentiation [261]. Furthermore, the presence of stimulated DCs was required for chondrogenic-differentiated MSC induction of human peripheral blood lymphocyte proliferation and cytotoxicity. On the other hand, osteogenic and adipogenic differentiation did not appear to alter the immunological properties of MSCs [261]. Therefore, the immunogenicity of MSCs following in vitro differentiation may depend on the resulting cell type obtained through differentiation.

In vitro cytokine-based neuronal differentiation has been found to cause increased hMSC expression of HLA molecules and costimulatory CD80 molecules, however, the proliferation of allogeneic peripheral blood lymphocytes could not be induced [262]. Instead, neuronal differentiated hMSCs suppressed the proliferation of peripheral blood lymphocytes induced by allogeneic lymphocytes or mitogens, through mechanisms involving cell-cell contact and soluble factors, such as TGF- $\beta 1$ and IL-10. Treatment with IFN- $\gamma$ enhanced the expression of HLA molecules by differentiated hMSCs, suggesting that an inflammatory environment in vivo could elicit increased immunogenicity of hMSCs. However, IFN- $\gamma$ exposure was unable to significantly up-regulate CD40, CD80 or CD86 expression, indicating that functional costimulatory signalling on neuronally differentiated hMSCs was incomplete. Also, peripheral blood lymphocyte proliferation was suppressed to a similar extent even after IFN- $\gamma$ treatment [262]. Further studies are required to more clearly elucidate the immunogenicity and immunomodulatory properties of hMSCs after neuronal differentiation, and it will be of interest to evaluate whether these factors may contribute to the lack of hMSC engraftment observed in some studies.

\section{Unresolved technical aspects of MSC transplantation in Parkinson's disease}

A number of technical aspects remain undetermined concerning the transplantation of MSCs into experimental models of CNS diseases. One of the primary concerns is the improvement of cell survival and differentiation post-transplantation. Graft survival can be linked to a number of factors, including the quantity of SCs used for transplantation. The majority of reported studies have transplanted MSCs at a dose of 100,000 cells per site in Parkinsonian rodent models $[81,218,223]$. For NSCs, transplantation of between 150,000 and 300,000 cells per site has been reported to be adequate for yielding graft survival, however, it was still suggested that use of higher numbers of SCs may result in higher survival rates [201]. Whereas, a separate report comparing the transplantation of $200,000,1$ million or 2 million human neural precursors into 6-OHDA hemiparkinsonian rats found that smaller grafts elicited greater neuronal fibre extension and less immunological rejection in comparison with larger grafts [203]. For MSCs, it was found that primate MSC engraftment into the primate CNS was enhanced when 'low'doses $(500,000)$ rather than high doses (2.5 million) of MSCs were injected intracerebrally [263]. Therefore, hMSC engraftment may be improved through increasing the number of hMSCs transplanted to a quantity more similar to that used in successful NSC transplantation or primate MSC transplantation.

Findings of glial scar formation at graft sites $[214,238,246]$ raise the question of whether the migration and integration of transplanted cells were prevented or inhibited. The glial scar formed at graft sites contains an inhibitory proteoglycan component; and the presence of inhibitory proteins, such as the chondroitin sulfate proteoglycans ACAN, versican, and neurocan, can inhibit axon guidance and prevent neurite outgrowth and axon regeneration [143,264-266]. Recent studies have attempted to improve graft survival and integration by creating a more permissive microenvironment at graft sites through chondroitinase ABC treatment to reduce inhibitory proteoglycans [246,267]. Combined transplantation of Müller SCs together with chondroitinase $\mathrm{ABC}$ has been employed for promotion of matrix degradation and cell migration in the degenerated retina [246]. This treatment in conjunction with enhanced microglial suppression resulted in dramatic improvement in migration of SCs into the retina, decreased microglial accumulation, significantly higher numbers of transplanted SCs, and a characteristic neuronal morphology in the migrating cells. These results suggest that abnormal extracellular matrix deposition and activation of innate inflammatory responses may constitute major barriers to retinal SC transplantation [246]. Furthermore, a combination of olfactory ensheathing cell and Schwann cell transplantation with chondroitinase $\mathrm{ABC}$ resulted in improved axonal regeneration and locomotor recovery after complete spinal cord transection [267].

Manipulation of the graft niche to facilitate cross-talk between transplanted SCs and the diseased brain has been proposed to aid transplantation in chronic lesions or advanced stages of neurodegenerative diseases in the aged CNS [268]. Evidence supporting 
this was seen with the over-expression of neural cell adhesion molecule L1 in donor NSCs and recipient transgenic MPTP-lesioned mice, which resulted in rapid and extensive distribution of donor NSCs, rescue of dysfunctional host dopaminergic neurons, and enhanced differentiation of donor NSCs into TH-expressing neurons [268]. These findings offer further options for more efficacious transplantation of SCs into the diseased CNS, and further studies are warranted.

Other strategies aimed at improving the survival and differentiation of SC and neuronal progenitor grafts have been suggested, including the addition of trophic factors, such as FGF-2 [269,270], or antioxidants [271] to the cell suspension prior to transplantation. Furthermore, little is known of the optimal timing or therapeutic window for SC transplantation post-injury. In liver fibrosis treatment, immediate systemic infusion of MSCs post-injury was able to significantly reduce liver damage and collagen deposition, whereas delaying MSC infusion by 1 week hampered the prevention of disease progression [272]. Unfortunately, no conclusions have been reached on which techniques or combinations of techniques provide the best outcomes and further investigation into these aspects is necessary.

\section{Summary/Conclusion}

A variety of distinct approaches have been implemented in the quest for MSC dopaminergic neuronal differentiation and application in potential PD therapies. Nonetheless, the reported findings possess a number of unifying elements, although these mainly lie in the realm of newly raised questions and issues that remain to be resolved. In the midst of these pertinent issues, are questions regarding the optimal developmental point at which to transplant differentiating cells, the relevance of animal models and studies to the situation in humans, the little-defined potential immunological responses to undifferentiated and differentiated MSC grafts, and the suitability for translation into the clinic. A meticulous and systematic approach is therefore required for the proper development of reproducible and reliable methods for MSC neuronal differentiation and application in cellular therapies for neurological diseases. While much progress has been achieved and promising results have been obtained, the generation of mature functional midbrain dopaminergic neurons from MSCs remains elusive. However, although improvements to our current understanding of MSC-based cellular therapies for PD are still required, the progress in this field to date validates the significance of this work and renders continued research efforts in this field as worthwhile pursuits.

\section{References}

1. Friedenstein AJ, Piatetzky S, II, Petrakova KV (1966) Osteogenesis in transplants of bone marrow cells. J Embryol Exp Morphol 16: 381-390.

2. Friedenstein AJ, Petrakova KV, Kurolesova Al, Frolova GP (1968) Heterotopic of bone marrow.Analysis of precursor cells for osteogenic and hematopoietic tissues. Transplantation 6: 230-247.

3. Friedenstein AJ, Chailakhjan RK, Lalykina KS (1970) The development of fibroblast colonies in monolayer cultures of guinea-pig bone marrow and spleen cells. Cell \& Tissue Kinet 3: 393-403.

4. Friedenstein AJ, Deriglasova UF, Kulagina NN, Panasuk AF, Rudakowa SF et al. (1974) Precursors for fibroblasts in different populations of hematopoietic cells as detected by the in vitro colony assay method. Exp Hematol 2: 83-92.

5. Friedenstein AJ, Chailakhyan RK, Gerasimov UV (1987) Bone marrow osteogenic stem cells: in vitro cultivation and transplantation in diffusion chambers. Cell Tissue Kinet 20: 263-272.

6. Howlett CR, Cave J, Williamson M, Farmer J, Ali SY, et al. (1986) Mineralization in in vitro cultures of rabbit marrow stromal cells. Clin Orthop Relat Res: 251 263.

7. Beresford JN, Bennett JH, Devlin C, Leboy PS, Owen ME (1992) Evidence for an inverse relationship between the differentiation of adipocytic and osteogenic cells in rat marrow stromal cell cultures. J Cell Sci 102: 341-351.

8. Rickard DJ, Sullivan TA, Shenker BJ, Leboy PS, Kazhdan I (1994) Induction of rapid osteoblast differentiation in rat bone marrow stromal cell cultures by dexamethasone and BMP-2. Dev Biol 161: 218-228.

9. Cheng SL, Yang JW, Rifas L, Zhang SF, Avioli LV (1994) Differentiation of human bone marrow osteogenic stromal cells in vitro: induction of the osteoblas phenotype by dexamethasone. Endocrinology 134: 277-286.

10. Johnstone B, Hering TM, Caplan AI, Goldberg VM, Yoo JU (1998) In vitro chondrogenesis of bone marrow-derived mesenchymal progenitor cells. Exp Cell Res 238: 265-272

11. Mackay AM, Beck SC, Murphy JM, Barry FP, Chichester CO, et al. (1998) Chondrogenic differentiation of cultured human mesenchymal stem cells from marrow. Tissue Eng 4: 415-428.

12. Lanotte M, Scott D, Dexter TM, Allen TD (1982) Clonal preadipocyte cel lines with different phenotypes derived from murine marrow stroma: factors influencing growth and adipogenesis in vitro. J Cell Physiol 111: 177-186.

13. Wakitani S, Saito T, Caplan Al (1995) Myogenic cells derived from rat bone marrow mesenchymal stem cells exposed to 5-azacytidine. Muscle Nerve 18 : 1417-1426.

14. Di Nicola M, Carlo-Stella C, Magni M, Milanesi M, Longoni PD, et al. (2002) Human bone marrow stromal cells suppress T-lymphocyte proliferation induced by cellular or nonspecific mitogenic stimuli. Blood 99: 3838-3843.

15. Krampera M, Glennie S, Dyson J, Scott D, Laylor R, et al. (2003) Bone marrow mesenchymal stem cells inhibit the response of naive and memory antigenspecific T cells to their cognate peptide. Blood 101: 3722-3729.

16. Le Blanc K, Tammik L, Sundberg B, Haynesworth SE, Ringden O (2003) Mesenchymal stem cells inhibit and stimulate mixed lymphocyte cultures and mitogenic responses independently of the major histocompatibility complex. Scand J Immunol 57: 11-20.

17. Kopen GC, Prockop DJ, Phinney DG (1999) Marrow stromal cells migrate throughout forebrain and cerebellum, and they differentiate into astrocytes after injection into neonatal mouse brains. Proc Natl Acad Sci U S A 96: 10711 10716.

18. Sanchez-Ramos J, Song S, Cardozo-Pelaez F, Hazzi C, Stedeford T, et al. (2000) Adult bone marrow stromal cells differentiate into neural cells in vitro. Exp Neurol 164: 247-256.

19. Woodbury D, Schwarz EJ, Prockop DJ, Black IB (2000) Adult rat and human bone marrow stromal cells differentiate into neurons. J Neurosci Res 61: 364 370 .

20. Chen J, Li Y, Wang L, Lu M, Zhang X, et al. (2001) Therapeutic benefit of intracerebral transplantation of bone marrow stromal cells after cerebral ischemia in rats. J Neurol Sci 189: 49-57.

21. Zhao LR, Duan WM, Reyes M, Keene CD, Verfaillie CM, et al. (2002) Human bone marrow stem cells exhibit neural phenotypes and ameliorate neurological deficits after grafting into the ischemic brain of rats. Exp Neurol 174: 11-20.

22. Munoz-Elias G, Marcus AJ, Coyne TM, Woodbury D, Black IB (2004) Adult bone marrow stromal cells in the embryonic brain: engraftment, migration, differentiation, and long-term survival. J Neurosci 24: 4585-4595.

23. Jiang Y, Jahagirdar BN, Reinhardt RL, Schwartz RE, Keene CD, et al. (2002) Pluripotency of mesenchymal stem cells derived from adult marrow. Nature 418: 41-49.

24. Jiang Y, Henderson D, Blackstad M, Chen A, Miller RF, et al. (2003) Neuroectodermal differentiation from mouse multipotent adult progenitor cells. Proc Natl Acad Sci U S A 100: 11854-11860.

25. Hermann A, Gastl R, Liebau S, Popa MO, Fiedler J, et al. (2004) Efficient generation of neural stem cell-like cells from adult human bone marrow stroma cells. J Cell Sci 117: 4411-4422.

26. Tao H, Rao R, Ma DD (2005) Cytokine-induced stable neuronal differentiation of human bone marrow mesenchymal stem cells in a serum/feeder cell-free condition. Dev Growth Differ 47: 423-433.

27. Schwartz RE, Reyes M, Koodie L, Jiang Y, Blackstad M, et al. (2002) Multipoten adult progenitor cells from bone marrow differentiate into functional hepatocytelike cells. J Clin Invest 109: 1291-1302. 
Citation: Khoo MLM, Tao H, Ma DDF (2011) Mesenchymal Stem Cell-Based Therapies for Parkinson's Disease: Progress, Controversies and Lessons for the Future. J Stem Cell Res Ther S2:005. doi:10.4172/2157-7633.S2-005

Page 19 of 24

28. Wang PP, Wang JH, Yan ZP, Hu MY, Lau GK, et al. (2004) Expression of hepatocyte-like phenotypes in bone marrow stromal cells after HGF induction. Biochem Biophys Res Commun 320: 712-716

29. Anderson DJ, Gage FH, Weissman IL (2001) Can stem cells cross lineage boundaries? Nat Med 7: 393-395

30. Blau HM, Brazelton TR, Weimann JM (2001) The evolving concept of a stem cell: entity or function? Cell 105: 829-841.

31. Morrison SJ (2001) Stem cell potential: can anything make anything? Curr Bio 11: R7-R9.

32. Orkin SH, Zon LI (2002) Hematopoiesis and stem cells: plasticity versus developmental heterogeneity. Nat Immunol 3: 323-328.

33. Lemischka I (2002) A few thoughts about the plasticity of stem cells. Exp Hematol 30: 848-852.

34. Goodell MA (2003) Stem-cell "plasticity": befuddled by the muddle. Curr Opin Hematol 10: 208-213.

35. Eisenberg LM, Eisenberg CA (2003) Stem cell plasticity, cell fusion, and transdifferentiation. Birth Defects Res C Embryo Today 69: 209-218.

36. Wagers AJ, Weissman IL (2004) Plasticity of adult stem cells. Cell 116: 639648

37. Phinney DG, Prockop DJ (2007) Concise review: mesenchymal stem/ multipotent stromal cells: the state of transdifferentiation and modes of tissue repair--current views. Stem Cells 25: 2896-2902.

38. Prockop DJ (2007) "Stemness" does not explain the repair of many tissues by mesenchymal stem/multipotent stromal cells (MSCs). Clin Pharmacol Ther 82 241-243.

39. Deng W, Obrocka M, Fischer I, Prockop DJ (2001) In vitro differentiation of human marrow stromal cells into early progenitors of neural cells by conditions that increase intracellular cyclic AMP. Biochem Biophys Res Commun. 282 148-152.

40. Tremain N, Korkko J, Ibberson D, Kopen GC, DiGirolamo C, et al. (2001) MicroSAGE analysis of 2,353 expressed genes in a single cell-derived colony of undifferentiated human mesenchymal stem cells reveals mRNAs of multiple cell lineages. Stem Cells 19: 408-418.

41. Woodbury D, Reynolds K, Black IB (2002) Adult bone marrow stromal stem cells express germline, ectodermal, endodermal, and mesodermal genes prior to neurogenesis. J Neurosci Res 69: 908-917.

42. Seshi B, Kumar S, King D (2003) Multilineage gene expression in human bone marrow stromal cells as evidenced by single-cell microarray analysis. Blood Cells Mol Dis 31: 268-285.

43. Wislet-Gendebien S, Leprince P, Moonen G, Rogister B (2003) Regulation of neural markers nestin and GFAP expression by cultivated bone marrow stromal cells. J Cell Sci 116: 3295-3302.

44. Vogel W, Grunebach F, Messam CA, Kanz L, Brugger W, et al. (2003) Heterogeneity among human bone marrow-derived mesenchymal stem cells and neural progenitor cells. Haematologica 88: 126-133.

45. Tondreau T, Lagneaux L, Dejeneffe M, Massy M, Mortier C, et al. (2004) Bone marrow-derived mesenchymal stem cells already express specific neural proteins before any differentiation. Differentiation 72: 319-326.

46. Suon S, Jin H, Donaldson AE, Caterson EJ, Tuan RS, et al. (2004) Transient differentiation of adult human bone marrow cells into neuron-like cells in culture: development of morphological and biochemical traits is mediated by different molecular mechanisms. Stem Cells Dev 13: 625-635.

47. Minguell JJ, Fierro FA, Epunan MJ, Erices AA, Sierralta WD (2005) Nonstimulated human uncommitted mesenchymal stem cells express cell markers of mesenchymal and neural lineages. Stem Cells Dev 14: 408-414.

48. Blondheim NR, Levy YS, Ben-Zur T, Burshtein A, Cherlow T, et al. (2006) Human mesenchymal stem cells express neural genes, suggesting a neural predisposition. Stem Cells Dev 15: 141-164

49. Deng J, Petersen BE, Steindler DA, Jorgensen ML, Laywell ED (2006) Mesenchymal stem cells spontaneously express neural proteins in culture and are neurogenic after transplantation. Stem Cells 24: 1054-1064.

50. Lamoury FM, Croitoru-Lamoury J, Brew BJ (2006) Undifferentiated mouse mesenchymal stem cells spontaneously express neural and stem cell markers Oct-4 and Rex-1. Cytotherapy 8: 228-242.

51. Phinney DG, Hill K, Michelson C, DuTreil M, Hughes C, et al. (2006) Biological activities encoded by the murine mesenchymal stem cell transcriptome provide a basis for their developmental potential and broad therapeutic efficacy. Stem Cells 24: 186-198

52. Azizi SA, Stokes D, Augelli BJ, DiGirolamo C, Prockop DJ (1998) Engraftment and migration of human bone marrow stromal cells implanted in the brains of albino rats-- similarities to astrocyte grafts. Proc Natl Acad Sci U S A 95 3908-3913.

53. Li Y, Chopp M, Chen J, Wang L, Gautam SC, et al. (2000) Intrastriatal transplantation of bone marrow nonhematopoietic cells improves functional recovery after stroke in adult mice. J Cereb Blood Flow Metab 20: 1311-1319.

54. Li Y, Chen J, Wang L, Lu M, Chopp M (2001) Treatment of stroke in rat with intracarotid administration of marrow stromal cells. Neurology 56: 1666-1672.

55. Lu D, Mahmood A, Wang L, Li Y, Lu M, et al. (2001) Adult bone marrow stromal cells administered intravenously to rats after traumatic brain injury migrate into brain and improve neurological outcome. Neuroreport 12: 559-563.

56. Mahmood A, Lu D, Wang L, Li Y, Lu M, et al. (2001) Treatment of traumatic brain injury in female rats with intravenous administration of bone marrow stromal cells. Neurosurgery 49: 1196-1203; discussion 1203-1204.

57. Mahmood A, Lu D, Wang L, Chopp M (2002) Intracerebral transplantation of marrow stromal cells cultured with neurotrophic factors promotes functional recovery in adult rats subjected to traumatic brain injury. J Neurotrauma 19 1609-1617.

58. Mahmood A, Lu D, Lu M, Chopp M (2003) Treatment of traumatic brain injury in adult rats with intravenous administration of human bone marrow stromal cells. Neurosurgery 53: 697-702; discussion 702-723.

59. Kim BJ, Seo JH, Bubien JK, Oh YS (2002) Differentiation of adult bone marrow stem cells into neuroprogenitor cells in vitro. Neuroreport 13: 1185-1188.

60. Jin K, Mao XO, Batteur S, Sun Y, Greenberg DA (2003) Induction of neuronal markers in bone marrow cells: differential effects of growth factors and patterns of intracellular expression. Exp Neurol 184: 78-89.

61. Kondo T, Johnson SA, Yoder MC, Romand R, Hashino E (2005) Sonic hedgehog and retinoic acid synergistically promote sensory fate specification from bone marrow- derived pluripotent stem cells. Proc Natl Acad Sci U S A 102: $4789-4794$

62. Guo L, Yin F, Meng HQ, Ling L, Hu-He TN, et al. (2005) Differentiation of mesenchymal stem cells into dopaminergic neuron-like cells in vitro. Biomed Environ Sci 18: 36-42.

63. Long X, Olszewski M, Huang W, Kletzel M (2005) Neural cell differentiation in vitro from adult human bone marrow mesenchymal stem cells. Stem Cells Dev 14: 65-69.

64. Joannides A, Gaughwin P, Scott M, Watt S, Compston A, et al. (2003) Postnatal astrocytes promote neural induction from adult human bone marrow-derived stem cells. Journal of Hematotherapy \& Stem Cell Research 12: 681-688.

65. Suzuki H, Taguchi T, Tanaka H, Kataoka H, Li Z, et al. (2004) Neurospheres induced from bone marrow stromal cells are multipotent for differentiation into neuron, astrocyte, and oligodendrocyte phenotypes. Biochem Biophys Res Commun 322: 918-922

66. Munoz-Elias G, Woodbury D, Black IB (2003) Marrow stromal cells, mitosis, and neuronal differentiation: stem cell and precursor functions. Stem Cells 21: 437-448.

67. Rismanchi N, Floyd CL, Berman RF, Lyeth BG (2003) Cell death and longterm maintenance of neuron-like state after differentiation of rat bone marrow stromal cells: a comparison of protocols. Brain Res 991: 46-55.

68. Hung SC, Cheng H, Pan CY, Tsai MJ, Kao LS, et al. (2002) In vitro differentiation of size-sieved stem cells into electrically active neural cells. Stem Cells 20: 522 529

69. Qu TY, Dong XJ, Sugaya I, Vaghani A, Pulido J, et al. (2004) Bromodeoxyuridine increases multipotency of human bone marrow-derived stem cells. Restor Neurol Neurosci 22: 459-468.

70. Lu P, Blesch A, Tuszynski MH (2004) Induction of bone marrow stromal cells 
Citation: Khoo MLM, Tao H, Ma DDF (2011) Mesenchymal Stem Cell-Based Therapies for Parkinson's Disease: Progress, Controversies and Lessons for the Future. J Stem Cell Res Ther S2:005. doi:10.4172/2157-7633.S2-005

Page 20 of 24

to neurons: differentiation, transdifferentiation, or artifact? J Neurosci Res 77: 174-191.

71. Neuhuber B, Gallo G, Howard L, Kostura L, Mackay A, et al. (2004) Reevaluation of in vitro differentiation protocols for bone marrow stromal cells: disruption of actin cytoskeleton induces rapid morphological changes and mimics neuronal phenotype. J Neurosci Res 77: 192-204

72. Bertani N, Malatesta P, Volpi G, Sonego P, Perris R (2005) Neurogenic potential of human mesenchymal stem cells revisited: analysis by immunostaining, timelapse video and microarray. J Cell Sci 118: 3925-3936.

73. Choi CB, Cho YK, Prakash KV, Jee BK, Han CW, et al. (2006) Analysis of neuron- like differentiation of human bone marrow mesenchymal stem cells. Biochem Biophys Res Commun 350: 138-146.

74. Suon S, Yang M, lacovitti L (2006) Adult human bone marrow stromal spheres express neuronal traits in vitro and in a rat model of Parkinson's disease. Brain Res 1106: 46-51

75. Song H, Stevens CF, Gage FH (2002) Astroglia induce neurogenesis from adult neural stem cells. Nature 417: 39-44.

76. Song HJ, Stevens CF, Gage FH (2002) Neural stem cells from adult hippocampus develop essential properties of functional CNS neurons. Nature Neuroscience 5: 438-445.

77. Alexanian AR (2005) Neural stem cells induce bone-marrow-derived mesenchymal stem cells to generate neural stem-like cells via juxtacrine and paracrine interactions. Exp Cell Res 310: 383-391.

78. Wislet-Gendebien S, Hans G, Leprince P, Rigo JM, Moonen G, et al. (2005) Plasticity of cultured mesenchymal stem cells: switch from nestin-positive to excitable neuron- like phenotype. Stem Cells 23: 392-402.

79. Abouelfetouh A, Kondoh T, Ehara K, Kohmura E (2004) Morphological differentiation of bone marrow stromal cells into neuron-like cells after coculture with hippocampal slice. Brain Res 1029: 114-119.

80. Kohyama J, Abe H, Shimazaki T, Koizumi A, Nakashima K, et al. (2001) Brain from bone: efficient "meta-differentiation" of marrow stroma-derived mature osteoblasts to neurons with Noggin or a demethylating agent. Differentiation 68: $235-244$.

81. Dezawa M, Kanno H, Hoshino M, Cho H, Matsumoto N, et al. (2004) Specific induction of neuronal cells from bone marrow stromal cells and application for autologous transplantation. J Clin Invest 113: 1701-1710.

82. Zhao LX, Zhang J, Cao F, Meng L, Wang DM, et al. (2004) Modification of the brain-derived neurotrophic factor gene: a portal to transform mesenchymal stem cells into advantageous engineering cells for neuroregeneration and neuroprotection. Exp Neurol 190: 396-406.

83. Svendsen CN, Bhattacharyya A, Tai YT (2001) Neurons from stem cells: preventing an identity crisis. Nat Rev Neurosci 2: 831-834.

84. Reh TA (2002) Neural stem cells: form and function. Nat Neurosci 5: 392-394.

85. Lendahl U, Zimmerman LB, McKay RD (1990) CNS stem cells express a new class of intermediate filament protein. Cell 60: 585-595.

86. Sejersen T, Lendahl U (1993) Transient expression of the intermediate filament nestin during skeletal muscle development. J Cell Sci 106: 1291-1300.

87. Kachinsky AM, Dominov JA, Miller JB (1994) Myogenesis and the intermediate filament protein, nestin. Dev Biol 165: 216-228.

88. Vaittinen S, Lukka R, Sahlgren C, Hurme T, Rantanen J, et al. (2001) The expression of intermediate filament protein nestin as related to vimentin and desmin in regenerating skeletal muscle. J Neuropathol Exp Neurol 60: 588-597.

89. Mokry J, Nemecek S (1998) Angiogenesis of extra- and intraembryonic blood vessels is associated with expression of nestin in endothelial cells. Folia Bio 44: 155-161.

90. Mokry J, Nemecek S (1998) Immunohistochemical detection of intermediate filament nestin. Acta Medica 41: 73-80.

91. Klein T, Ling Z, Heimberg H, Madsen OD, Heller RS, et al. (2003) Nestin is expressed in vascular endothelial cells in the adult human pancreas. $J$ Histochem Cytochem 51: 697-706.

92. Niki T, Pekny M, Hellemans K, Bleser PD, Berg KV, et al. (1999) Class V intermediate filament protein nestin is induced during activation of rat hepatic stellate cells. Hepatology 29: 520-527.
93. Egerbacher M, Krestan R, Bock P (1995) Morphology, histochemistry, and differentiation of the cat's epiglottic cartilage: a supporting organ composed of elastic cartilage, fibrous cartilage, myxoid tissue, and fat tissue. Anat Rec 242: $471-482$

94. Hainfellner JA, Voigtlander T, Strobel T, Mazal PR, Maddalena AS, et al. (2001) Fibroblasts can express glial fibrillary acidic protein (GFAP) in vivo. $J$ Neuropathol Exp Neurol 60: 449-461.

95. Croft AP, Przyborski SA (2006) Formation of neurons by non-neural adult stem cells: potential mechanism implicates an artifact of growth in culture. Stem Cells 24: 1841-1851.

96. Khoo ML, Shen B, Tao H, Ma DD (2008) Long-term serial passage and neuronal differentiation capability of human bone marrow mesenchymal stem cells. Stem Cells Dev 17: 883-896.

97. Alvarez-Dolado M, Pardal R, Garcia-Verdugo JM, Fike JR, Lee HO, et al. (2003) Fusion of bone-marrow-derived cells with Purkinje neurons, cardiomyocytes and hepatocytes. Nature 425: 968-973.

98. Weimann JM, Johansson CB, Trejo A, Blau HM (2003) Stable reprogrammed heterokaryons form spontaneously in Purkinje neurons after bone marrow transplant. Nat Cell Biol 5: 959-966.

99. Terada N, Hamazaki T, Oka M, Hoki M, Mastalerz DM, et al. (2002) Bone marrow cells adopt the phenotype of other cells by spontaneous cell fusion. Nature 416: 542-545.

100. Cho KJ, Trzaska KA, Greco SJ, McArdle J, Wang FS, et al. (2005) Neurons derived from human mesenchymal stem cells show synaptic transmission and can be induced to produce the neurotransmitter substance $P$ by interleukin- 1 alpha. Stem Cells 23: 383-391.

101. Trzaska KA, Kuzhikandathil EV, Rameshwar P (2007) Specification of dopaminergic phenotype from adult human mesenchymal stem cells. Stem Cells 25: 2797-2808.

102. Greco SJ, Zhou C, Ye JH, Rameshwar P (2007) An interdisciplinary approach and characterization of neuronal cells transdifferentiated from human mesenchymal stem cells. Stem Cells Dev 16: 811-826.

103. Kan I, Ben-Zur T, Barhum Y, Levy YS, Burstein A, et al. (2007) Dopaminergic differentiation of human mesenchymal stem cells--utilization of bioassay for tyrosine hydroxylase expression. Neurosci Lett 419: 28-33.

104. Locatelli F, Maccario R, Frassoni F (2007) Mesenchymal stromal cells, from indifferent spectators to principal actors. Are we going to witness a revolution in the scenario of allograft and immune-mediated disorders? Haematologica 92: 872-877.

105. Stagg J (2007) Immune regulation by mesenchymal stem cells: two sides to the coin. Tissue Antigens 69: 1-9.

106. Aggarwal S, Pittenger MF (2005) Human mesenchymal stem cells modulate allogeneic immune cell responses. Blood 105: 1815-1822.

107. Beyth S, Borovsky Z, Mevorach D, Liebergall M, Gazit Z, et al. (2005) Human mesenchymal stem cells alter antigen-presenting cell maturation and induce T-cell unresponsiveness. Blood 105: 2214-2219.

108. Jiang XX, Zhang Y, Liu B, Zhang SX, Wu Y, et al. (2005) Human mesenchymal stem cells inhibit differentiation and function of monocyte-derived dendritic cells. Blood 105: 4120-4126.

109. Nauta AJ, Kruisselbrink AB, Lurvink E, Willemze R, Fibbe WE (2006) Mesenchymal stem cells inhibit generation and function of both CD34+ derived and monocyte- derived dendritic cells. J Immunol 177: 2080-2087.

110. Zhang W, Ge W, Li C, You S, Liao L, et al. (2004) Effects of mesenchymal stem cells on differentiation, maturation, and function of human monocytederived dendritic cells. Stem Cells Dev 13: 263-271.

111. Spaggiari GM, Capobianco A, Becchetti S, Mingari MC, Moretta L (2006) Mesenchymal stem cell-natural killer cell interactions: evidence that activated NK cells are capable of killing MSCs, whereas MSCs can inhibit IL-2-induced NK-cell proliferation. Blood 107: 1484-1490.

112. Rasmusson I, Ringden O, Sundberg B, Le Blanc K (2003) Mesenchymal stem cells inhibit the formation of cytotoxic $T$ lymphocytes, but not activated cytotoxic T lymphocytes or natural killer cells. Transplantation 76: 1208-1213.

113. Sotiropoulou PA, Perez SA, Gritzapis AD, Baxevanis CN, Papamichail M (2006) Interactions between human mesenchymal stem cells and natural kille cells. Stem Cells 24: 74-85. 
Citation: Khoo MLM, Tao H, Ma DDF (2011) Mesenchymal Stem Cell-Based Therapies for Parkinson's Disease: Progress, Controversies and Lessons for the Future. J Stem Cell Res Ther S2:005. doi:10.4172/2157-7633.S2-005

Page 21 of 24

114. Maccario R, Podesta M, Moretta A, Cometa A, Comoli P, et al. (2005) Interaction of human mesenchymal stem cells with cells involved in alloantigen-specific immune response favors the differentiation of CD4+ T-cell subsets expressing a regulatory/suppressive phenotype. Haematologica 90: 516-525.

115. Krampera M, Cosmi L, Angeli R, Pasini A, Liotta F, et al. (2006) Role for interferon- gamma in the immunomodulatory activity of human bone marrow mesenchymal stem cells. Stem Cells 24: 386-398.

116. Corcione A, Benvenuto F, Ferretti E, Giunti D, Cappiello V, et al. (2006) Human mesenchymal stem cells modulate B-cell functions. Blood 107: 367-372.

117. Augello A, Tasso R, Negrini SM, Amateis A, Indiveri F, et al. (2005) Bone marrow mesenchymal progenitor cells inhibit lymphocyte proliferation by activation of the programmed death 1 pathway. Eur J Immunol 35: 1482-1490.

118. Glennie S, Soeiro I, Dyson PJ, Lam EW, Dazzi F (2005) Bone marrow mesenchymal stem cells induce division arrest anergy of activated $\mathrm{T}$ cells. Blood 105: 2821-2827.

119. Bartholomew A, Sturgeon C, Siatskas M, Ferrer K, Mclntosh K, et al. (2002) Mesenchymal stem cells suppress lymphocyte proliferation in vitro and prolong skin graft survival in vivo. Exp Hematol 30: 42-48.

120. Tse WT, Pendleton JD, Beyer WM, Egalka MC, Guinan EC (2003) Suppression of allogeneic T-cell proliferation by human marrow stromal cells: implications in transplantation. Transplantation 75: 389-397.

121.Djouad F, Plence P, Bony C, Tropel P, Apparailly F, et al. (2003) Immunosuppressive effect of mesenchymal stem cells favors tumor growth in allogeneic animals. Blood 102: 3837-3844.

122. Rasmusson I, Ringden O, Sundberg B, Le Blanc K (2005) Mesenchymal stem cells inhibit lymphocyte proliferation by mitogens and alloantigens by different mechanisms. Exp Cell Res 305: 33-41.

123. Meisel R, Zibert A, Laryea M, Gobel U, Daubener W, et al. (2004) Human bone marrow stromal cells inhibit allogeneic T-cell responses by indoleamine 2,3- dioxygenase-mediated tryptophan degradation. Blood 103: 4619-4621.

124. Sato K, Ozaki K, Oh I, Meguro A, Hatanaka K, et al. (2007) Nitric oxide plays a critical role in suppression of T-cell proliferation by mesenchymal stem cells. Blood 109: 228-234.

125. Chamberlain G, Fox J, Ashton B, Middleton J (2007) Concise review: mesenchymal stem cells: their phenotype, differentiation capacity, immunological features, and potential for homing. Stem Cells 25: 2739-2749.

126. Nauta AJ, Fibbe WE (2007) Immunomodulatory properties of mesenchyma stromal cells. Blood 110: 3499-3506.

127. Ramasamy R, Lam EW, Soeiro I, Tisato V, Bonnet D, et al. (2007) Mesenchymal stem cells inhibit proliferation and apoptosis of tumor cells: impact on in vivo tumor growth. Leukemia 21: 304-310.

128. Ramasamy R, Tong CK, Seow HF, Vidyadaran S, Dazzi F (2008) The immunosuppressive effects of human bone marrow-derived mesenchymal stem cells target $\mathrm{T}$ cell proliferation but not its effector function. Cell Immunol 251: $131-136$.

129.Deng W, Han Q, Liao L, You S, Deng H, et al. (2005) Effects of allogeneic bone marrow-derived mesenchymal stem cells on $\mathrm{T}$ and $\mathrm{B}$ lymphocytes from BXSB mice. DNA Cell Biol 24: 458-463.

130.Spaggiari GM, Capobianco A, Abdelrazik H, Becchetti F, Mingari MC, et al. (2008) Mesenchymal stem cells inhibit natural killer-cell proliferation, cytotoxicity, and cytokine production: role of indoleamine 2,3-dioxygenase and prostaglandin E2. Blood 111: 1327-1333.

131. Le Blanc K, Ringden O (2005) Immunobiology of human mesenchymal stem cells and future use in hematopoietic stem cell transplantation. Biol Blood Marrow Transplant 11: 321-334.

132. Fibbe WE, Nauta AJ, Roelofs $H$ (2007) Modulation of immune responses by mesenchymal stem cells. Ann N Y Acad Sci 1106: 272-278.

133. Liechty KW, MacKenzie TC, Shaaban AF, Radu A, Moseley AM, et al. (2000) Human mesenchymal stem cells engraft and demonstrate site-specific differentiation after in utero transplantation in sheep. Nat Med 6: 1282-1286.

134. Airey JA, Almeida-Porada G, Colletti EJ, Porada CD, Chamberlain J, et al. (2004) Human mesenchymal stem cells form Purkinje fibers in fetal sheep heart. Circulation 109: 1401-1407.

135. Le Blanc K, Rasmusson I, Sundberg B, Gotherstrom C, Hassan M, et al.
(2004) Treatment of severe acute graft-versus-host disease with third party haploidentical mesenchymal stem cells. Lancet 363: 1439-1441.

136. Yanez R, Lamana ML, Garcia-Castro J, Colmenero I, Ramirez M, et al (2006) Adipose tissue-derived mesenchymal stem cells have in vivo immunosuppressive properties applicable for the control of the graft-versushost disease. Stem Cells 24: 2582-2591.

137. Sudres M, Norol F, Trenado A, Gregoire S, Charlotte F, et al. (2006) Bone marrow mesenchymal stem cells suppress lymphocyte proliferation in vitro but fail to prevent graft-versus-host disease in mice. J Immunol 176: 7761-7767.

138. Horwitz EM, Gordon PL, Koo WK, Marx JC, Neel MD, et al. (2002) Isolated allogeneic bone marrow-derived mesenchymal cells engraft and stimulate growth in children with osteogenesis imperfecta: Implications for cell therapy of bone. Proc Natl Acad Sci U S A 99: 8932-8937.

139. Grinnemo KH, Mansson A, Dellgren G, Klingberg D, Wardell E, et al. (2004) Xenoreactivity and engraftment of human mesenchymal stem cells transplanted into infarcted rat myocardium. J Thorac Cardiovasc Surg 127 1293-1300.

140. Nauta AJ, Westerhuis G, Kruisselbrink AB, Lurvink EG, Willemze $R$, et al. (2006) Donor-derived mesenchymal stem cells are immunogenic in an allogeneic host and stimulate donor graft rejection in a nonmyeloablative setting. Blood 108: 2114-2120.

141. Eliopoulos N, Stagg J, Lejeune L, Pommey S, Galipeau J (2005) Allogeneic marrow stromal cells are immune rejected by MHC class I- and class IImismatched recipient mice. Blood 106: 4057-4065.

142. Ma DD, Da WM, Purvis-Smith S, Biggs JC (1987) Chromosomal analysis of bone marrow stromal fibroblasts in allogeneic HLA compatible sibling bone marrow transplantations. Leuk Res 11: 661-663.

143. Horner PJ, Gage FH (2002) Regeneration in the adult and aging brain. Arch Neurol 59: 1717-1720

144. Ourednik V, Ourednik J (2004) Multifaceted dialogue between graft and host in neurotransplantation. J Neurosci Res 76: 193-204.

145. Cotran RS, Kumar V, Collins T (1999) Robbins Pathologic Basis of Disease 6 th ed, W.B. Saunders Company, Philadelphia.

146. Gelb DJ, Oliver E, Gilman S (1999) Diagnostic criteria for Parkinson disease. Arch Neurol 56: 33-39.

147.Schulz JB, Falkenburger BH (2004) Neuronal pathology in Parkinson's disease. Cell Tissue Res 318: 135-147.

148. Klockgether T (2004) Parkinson's disease: clinical aspects. Cell Tissue Res 318: $115-120$

149.Teismann P, Schulz JB (2004) Cellular pathology of Parkinson's disease: astrocytes, microglia and inflammation. Cell Tissue Res 318: 149-161.

150.Dunnett SB, Bjorklund A (1999) Prospects for new restorative and neuroprotective treatments in Parkinson's disease. Nature 399: A32-A39.

151.Langston JW (1998) Epidemiology versus genetics in Parkinson's disease: progress in resolving an age-old debate. Ann Neurol 44: S45-S52.

152. Orr CF, Rowe DB, Halliday GM (2002) An inflammatory review of Parkinson's disease. Prog Neurobiol 68: 325-340.

153. Bernheimer H, Birkmayer W, Hornykiewicz O, Jellinger K, Seitelberger F (1973) Brain dopamine and the syndromes of Parkinson and Huntington. Clinical, morphological and neurochemical correlations. J Neurol Sci 20: 415 455.

154. Fearnley JM, Lees AJ (1991) Ageing and Parkinson's disease: substantia nigra regional selectivity. Brain 114: 2283-2301.

155. Veldman BA, Wijn AM, Knoers N, Praamstra P, Horstink MW (1998) Genetic and environmental risk factors in Parkinson's disease. Clin Neurol Neurosurg 100: $15-26$

156. Gasser T (1998) Genetics of Parkinson's disease. Ann Neurol 44: S53-S57.

157. Olanow CW, Tatton WG (1999) Etiology and pathogenesis of Parkinson's disease. Annu Rev Neurosci 22: 123-144.

158. Brooks DJ (1998) The early diagnosis of Parkinson's disease. Ann Neurol 44 S10-S18.

159. Dick FD (2006) Parkinson's disease and pesticide exposures. Br Med Bull 79-80: $219-231$ 
Citation: Khoo MLM, Tao H, Ma DDF (2011) Mesenchymal Stem Cell-Based Therapies for Parkinson's Disease: Progress, Controversies and Lessons for the Future. J Stem Cell Res Ther S2:005. doi:10.4172/2157-7633.S2-005

Page 22 of 24

160. Langston JW, Ballard P, Tetrud JW, Irwin I (1983) Chronic Parkinsonism in humans due to a product of meperidine-analog synthesis. Science 219: 979 980.

161.Davie CA (2008) A review of Parkinson's disease. Br Med Bull 86: 109-127.

162. Jenner $P$ (2008) Functional models of Parkinson's disease: a valuable tool in the development of novel therapies. Ann Neurol 64: S16-S29.

163. Schwarting RK, Huston JP (1996) The unilateral 6-hydroxydopamine lesion model in behavioral brain research. Analysis of functional deficits, recovery and treatments. Prog Neurobiol 50: 275-331.

164. Ungerstedt $U$ (1968) 6-Hydroxy-dopamine induced degeneration of central monoamine neurons. Eur J Pharmacol 5: 107-110.

165. Ungerstedt U, Arbuthnott GW (1970) Quantitative recording of rotational behavior in rats after 6-hydroxy-dopamine lesions of the nigrostriatal dopamine system. Brain Res 24: 485-493.

166. Sachs C, Jonsson G (1975) Mechanisms of action of 6-hydroxydopamine. Biochem Pharmacol 24: 1-8.

167. Henderson JM, Watson S, Halliday GM, Heinemann T, Gerlach M (2003) Relationships between various behavioural abnormalities and nigrostriatal dopamine depletion in the unilateral 6-OHDA-lesioned rat. Behav Brain Res 139: 105-113.

168. Gerlach M, Riederer P (1996) Animal models of Parkinson's disease: an empirical comparison with the phenomenology of the disease in man. $J$ Neural Transm 103: 987-1041.

169.Du Y, Ma Z, Lin S, Dodel RC, Gao F, et al. (2001) Minocycline prevents nigrostriatal dopaminergic neurodegeneration in the MPTP model of Parkinson's disease. Proc Natl Acad Sci U S A 98: 14669-14674.

170.Isacson O, Kordower JH (2008) Future of cell and gene therapies for Parkinson's disease. Ann Neurol 64: S122-S138.

171.Bjorklund A, Stenevi U (1979) Reconstruction of the nigrostriatal dopamine pathway by intracerebral nigral transplants. Brain Res 177: 555-560.

172. Perlow MJ, Freed WJ, Hoffer BJ, Seiger A, Olson L, et al. (1979) Brain grafts reduce motor abnormalities produced by destruction of nigrostriatal dopamine system. Science 204: 643-647.

173. Bjorklund A, Stenevi U, Dunnett SB, Iversen SD (1981) Functional reactivation of the deafferented neostriatum by nigral transplants. Nature 289: 497-499.

174. Wuerthele SM, Freed WJ, Olson L, Morihisa J, Spoor L, et al. (1981) Effect of dopamine agonists and antagonists on the electrical activity of substantia nigra neurons transplanted into the lateral ventricle of the rat. Exp Brain Res 44: 1-10.

175. Dunnett SB, Bjorklund A, Stenevi U, Iversen SD (1981) Behavioural recovery following transplantation of substantia nigra in rats subjected to 6-OHDA lesions of the nigrostriatal pathway. I. Unilateral lesions. Brain Res 215: 147161.

176. Redmond DE, Sladek JR, Jr., Roth RH, Collier TJ, Elsworth JD, et al. (1986) Fetal neuronal grafts in monkeys given methylphenyltetrahydropyridine. Lancet 1: 1125-1127.

177. Brundin P, Nilsson OG, Strecker RE, Lindvall O, Astedt B, et al. (1986) Behavioural effects of human fetal dopamine neurons grafted in a rat model of Parkinson's disease. Exp Brain Res 65: 235-240.

178. Stromberg I, Bygdeman M, Goldstein M, Seiger A, Olson L (1986) Human fetal substantia nigra grafted to the dopamine-denervated striatum of immunosuppressed rats: evidence for functional reinnervation. Neurosci Lett 71: $271-276$.

179. Brundin P, Strecker RE, Widner H, Clarke DJ, Nilsson OG, et al. (1988) Human fetal dopamine neurons grafted in a rat model of Parkinson's disease: immunological aspects, spontaneous and drug-induced behaviour, and dopamine release. Exp Brain Res 70: 192-208.

180. Lindvall O, Rehncrona S, Gustavii B, Brundin P, Astedt B, et al. (1988) Feta dopamine-rich mesencephalic grafts in Parkinson's disease. Lancet 2: 14831484 .

181. Hitchcock ER, Clough C, Hughes R, Kenny B (1988) Embryos and Parkinson's disease. Lancet 1: 1274

182. Lindvall O, Rehncrona S, Brundin P, Gustavii B, Astedt B, et al. (1989) Human fetal dopamine neurons grafted into the striatum in two patients with severe
Parkinson's disease. A detailed account of methodology and a 6-month followup. Arch Neurol 46: 615-631.

183. Lindvall O, Brundin P, Widner H, Rehncrona S, Gustavii B, et al. (1990) Grafts of fetal dopamine neurons survive and improve motor function in Parkinson's disease. Science 247: 574-577.

184. Freed CR, Breeze RE, Rosenberg NL, Schneck SA, Kriek E, et al. (1992) Survival of implanted fetal dopamine cells and neurologic improvement 12 to 46 months after transplantation for Parkinson's disease. N Engl J Med 327 1549-1555.

185. Lindvall O, Sawle G, Widner H, Rothwell JC, Bjorklund A, et al. (1994) Evidence for long-term survival and function of dopaminergic grafts in progressive Parkinson's disease. Ann Neurol 35: 172-180.

186. Peschanski M, Defer G, N'Guyen JP, Ricolfi F, Monfort JC, et al. (1994) Bilateral motor improvement and alteration of L-dopa effect in two patients with Parkinson's disease following intrastriatal transplantation of foetal ventral mesencephalon. Brain 117: 487-499.

187. Freeman TB, Olanow CW, Hauser RA, Nauert GM, Smith DA, et al. (1995) Bilateral fetal nigral transplantation into the postcommissural putamen in Parkinson's disease. Ann Neurol 38: 379-388.

188. Kordower JH, Freeman TB, Snow BJ, Vingerhoets FJ, Mufson EJ, et al. (1995) Neuropathological evidence of graft survival and striatal reinnervation after the transplantation of fetal mesencephalic tissue in a patient with Parkinson's disease. N Engl J Med 332: 1118-1124.

189. Wenning GK, Odin P, Morrish P, Rehncrona S, Widner H, et al. (1997) Shortand long-term survival and function of unilateral intrastriatal dopaminergic grafts in Parkinson's disease. Ann Neurol 42: 95-107.

190. Hagell P, Schrag A, Piccini P, Jahanshahi M, Brown R, et al. (1999) Sequential bilateral transplantation in Parkinson's disease: effects of the second graft. Brain 122: 1121-1132

191. Hauser RA, Freeman TB, Snow BJ, Nauert M, Gauger L, et al. (1999) Longterm evaluation of bilateral fetal nigral transplantation in Parkinson disease. Arch Neurol 56: 179-187.

192. Brundin P, Pogarell O, Hagell P, Piccini P, Widner H, et al. (2000) Bilatera caudate and putamen grafts of embryonic mesencephalic tissue treated with lazaroids in Parkinson's disease. Brain 123: 1380-1390.

193. Freed CR, Greene PE, Breeze RE, Tsai WY, DuMouchel W, et al. (2001) Transplantation of embryonic dopamine neurons for severe Parkinson's disease. N Engl J Med 344: 710-719.

194. Olanow CW, Goetz CG, Kordower JH, Stoessl AJ, Sossi V, et al. (2003) A double- blind controlled trial of bilateral fetal nigral transplantation in Parkinson's disease. Annals of Neurology 54: 403-414.

195. Svendsen C (2008) Stem cells and Parkinson's disease: toward a treatment, not a cure. Cell Stem Cell 2: 412-413.

196. Piccini P, Brooks DJ, Bjorklund A, Gunn RN, Grasby PM, et al. (1999) Dopamine release from nigral transplants visualized in vivo in a Parkinson's patient. Nature Neuroscience 2: 1137-1140.

197. Kordower JH, Chu Y, Hauser RA, Freeman TB, Olanow CW (2008) Lewy body-like pathology in long-term embryonic nigral transplants in Parkinson's disease. Nat Med 14: 504-506.

198. Mendez I, Vinuela A, Astradsson A, Mukhida K, Hallett P, et al. (2008) Dopamine neurons implanted into people with Parkinson's disease survive without pathology for 14 years. Nat Med 14: 507-509.

199. Li JY, Englund E, Holton JL, Soulet D, Ha gell P, et al. (2008) Lewy bodies in grafted neurons in subjects with Parkinson's disease suggest host-to-graft disease propagation. Nat Med 14: 501-503

200. Sayles M, Jain M, Barker RA (2004) The cellular repair of the brain in Parkinson's disease--past, present and future. Transpl Immunol 12: 321-342.

201. Svendsen CN, Clarke DJ, Rosser AE, Dunnett SB (1996) Survival and differentiation of rat and human epidermal growth factor-responsive precursor cells following grafting into the lesioned adult central nervous system. Exp Neurol 137: 376-388.

202. Svendsen CN, Caldwell MA, Shen J, ter Borg MG, Rosser AE, et al. (1997) Long- term survival of human central nervous system progenitor cells transplanted into a rat model of Parkinson's disease. Exp Neurol 148: 135 146. 
Citation: Khoo MLM, Tao H, Ma DDF (2011) Mesenchymal Stem Cell-Based Therapies for Parkinson's Disease: Progress, Controversies and Lessons for the Future. J Stem Cell Res Ther S2:005. doi:10.4172/2157-7633.S2-005

Page 23 of 24

203. Ostenfeld T, Caldwell MA, Prowse KR, Linskens MH, Jauniaux E, et al. (2000) Human neural precursor cells express low levels of telomerase in vitro and show diminishing cell proliferation with extensive axonal outgrowth following transplantation. Exp Neurol 164: 215-226.

204. Studer L, Tabar V, McKay RD (1998) Transplantation of expanded mesencephalic precursors leads to recovery in parkinsonian rats. Nature Neuroscience 1: 290-295.

205. Murrell W, Wetzig A, Donnellan M, Feron F, Burne T, et al. (2008) Olfactory mucosa is a potential source for autologous stem cell therapy for Parkinson's disease. Stem Cells 26: 2183-2192.

206. Lee SH, Lumelsky N, Studer L, Auerbach JM, McKay RD (2000) Efficient generation of midbrain and hindbrain neurons from mouse embryonic stem cells. Nature Biotechnology 18: 675-679.

207. Bjorklund LM, Sanchez-Pernaute R, Chung S, Andersson T, Chen IY, et al (2002) Embryonic stem cells develop into functional dopaminergic neurons after transplantation in a Parkinson rat model.[see comment]. Proceedings of the National Academy of Sciences of the United States of America 99: 23442349 .

208. Kim JH, Auerbach JM, Rodriguez-Gomez JA, Velasco I, Gavin D, et al. (2002) Dopamine neurons derived from embryonic stem cells function in an animal model of Parkinson's disease. Nature 418: 50-56.

209. Tabar V, Tomishima M, Panagiotakos G, Wakayama S, Menon J, et al. (2008) Therapeutic cloning in individual parkinsonian mice. Nat Med 14: 379-381.

210. Wernig M, Zhao JP, Pruszak J, Hedlund E, Fu D, et al. (2008) Neurons derived from reprogrammed fibroblasts functionally integrate into the fetal brain and improve symptoms of rats with Parkinson's disease. Proc Natl Acad Sci U S A 105: 5856-5861.

211. Takahashi K, Yamanaka S (2006) Induction of pluripotent stem cells from mouse embryonic and adult fibroblast cultures by defined factors. Cell 126 663-676.

212. Yamanaka $S$ (2007) Strategies and new developments in the generation of patient- specific pluripotent stem cells. Cell Stem Cell 1: 39-49.

213. Kramer BC, Woodbury D, Black IB (2006) Adult rat bone marrow stromal cells express genes associated with dopamine neurons. Biochem Biophys Res Commun 343: 1045-1052.

214. Khoo ML, Tao H, Meedeniya AC, Mackay-Sim A, Ma DD (2011) Transplantation of neuronal-primed human bone marrow mesenchymal stem cells in hemiparkinsonian rodents. PLoS One 6: e19025.

215. Hermann A, Liebau S, Gastl R, Fickert S, Habisch HJ, et al. (2006) Comparative analysis of neuroectodermal differentiation capacity of human bone marrow stromal cells using various conversion protocols. J Neurosci Res 83: $1502-1514$.

216. Pacary E, Legros $H$, Valable $S$, Duchatelle $P$, Lecocq M, et al. (2006) Synergistic effects of $\mathrm{CoCl}(2)$ and $\mathrm{ROCK}$ inhibition on mesenchymal stem cell differentiation into neuron-like cells. J Cell Sci 119: 2667-2678.

217. Couches G, Sensebe L, Vourc'h P, Garreau L, Bodard S, et al. (2008) Partia recovery of dopaminergic pathway after graft of adult mesenchymal stem cells in a rat model of Parkinson's disease. Neurochem Int 52: 1332-1342.

218. Fu YS, Cheng YC, Lin MY, Cheng H, Chu PM, et al. (2006) Conversion of human umbilical cord mesenchymal stem cells in Wharton's jelly to dopaminergic neurons in vitro: potential therapeutic application for Parkinsonism. Stem Cells 24: $115-124$.

219. Barzilay R, Kan I, Ben-Zur T, Bulvik S, Melamed E, et al. (2008) Induction of human mesenchymal stem cells into dopamine-producing cells with different differentiation protocols. Stem Cells Dev 17: 547-554.

220.Zhang Z, Wang X, Wang S (2008) Isolation and characterization of mesenchymal stem cells derived from bone marrow of patients with Parkinson's disease. In Vitro Cell Dev Biol Anim 44: 169-177.

221. Kern S, Eichler H, Stoeve J, Kluter H, Bieback K (2006) Comparative analysis of mesenchymal stem cells from bone marrow, umbilical cord blood, or adipose tissue. Stem Cells 24: 1294-1301.

222. Li Y, Chen J, Wang L, Zhang L, Lu M, et al. (2001) Intracerebral transplantation of bone marrow stromal cells in a 1-methyl-4-phenyl-1,2,3,6-tetrahydropyridine mouse model of Parkinson's disease. Neurosci Lett 316: 67-70.

223. Hellmann MA, Panet H, Barhum Y, Melamed E, Offen D (2006) Increased survival and migration of engrafted mesenchymal bone marrow stem cells in 6- hydroxydopamine-lesioned rodents. Neurosci Lett 395: 124-128.

224. Roy NS, Cleren C, Singh SK, Yang L, Beal MF, et al. (2006) Functional engraftment of human ES cell-derived dopaminergic neurons enriched by coculture with telomerase-immortalized midbrain astrocytes. Nat Med 12: 1259-1268.

225. Kan I, Melamed E, Offen D, Green P (2007) Docosahexaenoic acid and arachidonic acid are fundamental supplements for the induction of neuronal differentiation. J Lipid Res 48: 513-517

226. Greco SJ, Rameshwar P (2007) Enhancing effect of IL-1alpha on neurogenesis from adult human mesenchymal stem cells: implication for inflammatory mediators in regenerative medicine. J Immunol 179: 3342-3350.

227. Yim EK, Pang SW, Leong KW (2007) Synthetic nanostructures inducing differentiation of human mesenchymal stem cells into neuronal lineage. Exp Cell Res 313: 1820-1829.

228. Isacson O, Deacon T (1997) Neural transplantation studies reveal the brain's capacity for continuous reconstruction. Trends Neurosci 20: 477-482.

229. Munoz JR, Stoutenger BR, Robinson AP, Spees JL, Prockop DJ (2005) Human stem/progenitor cells from bone marrow promote neurogenesis of endogenous neural stem cells in the hippocampus of mice. Proc Natl Acad Sci U S A 102: 18171-18176.

230. Ohtaki H, Ylostalo JH, Foraker JE, Robinson AP, Reger RL, et al. (2008) Stem/progenitor cells from bone marrow decrease neuronal death in global ischemia by modulation of inflammatory/immune responses. Proc Natl Acad Sci U S A 105: 14638-14643.

231. Shintani A, Nakao N, Kakishita K, Itakura T (2007) Protection of dopamine neurons by bone marrow stromal cells. Brain Res 1186: 48-55.

232. Bahat-Stroomza M, Barhum Y, Levy YS, Karpov O, Bulvik S, et al. (2009) Induction of Adult Human Bone Marrow Mesenchymal Stromal Cells into Functional Astrocyte-Like Cells: Potential for Restorative Treatment in Parkinson's Disease. J Mol Neurosci 39: 199-210.

233. Sadan O, Bahat-Stromza M, Barhum Y, Levy YS, Pisnevsky A, et al. (2009) Protective effects of neurotrophic factors secreting cells in a 6OHDA rat mode of Parkinson disease. Stem Cells Dev 18: 1179-1190.

234. Jin GZ, Cho SJ, Choi EG, Lee YS, Yu XF, et al. (2008) Rat mesenchymal stem cells increase tyrosine hydroxylase expression and dopamine content in ventral mesencephalic cells in vitro. Cell Biol Int 32: 1433-1438.

235. Hickey WF (2001) Basic principles of immunological surveillance of the norma central nervous system. Glia 36: 118-124.

236. Widner $\mathrm{H}$, Brundin $\mathrm{P}$ (1988) Immunological aspects of grafting in the mammalian central nervous system. A review and speculative synthesis. Brain Res 472: 287-324.

237. Barker RA, Widner H (2004) Immune problems in central nervous system cell therapy. NeuroRx 1: 472-481.

238. Coyne TM, Marcus AJ, Woodbury D, Black IB (2006) Marrow stromal cells transplanted to the adult brain are rejected by an inflammatory response and transfer donor labels to host neurons and glia. Stem Cells 24: 2483-2492.

239. Camp DM, Loeffler DA, Farrah DM, Borneman JN, LeWitt PA (2009) Cellular immune response to intrastriatally implanted allogeneic bone marrow stromal cells in a rat model of Parkinson's disease. J Neuroinflammation 6: 17.

240. Giulian D (1987) Ameboid microglia as effectors of inflammation in the central nervous system. J Neurosci Res 18: 155-71, 132-133.

241.Perry VH, Bell MD, Brown HC, Matyszak MK (1995) Inflammation in the nervous system. Curr Opin Neurobiol 5: 636-641.

242. Davalos D, Grutzendler J, Yang G, Kim JV, Zuo Y, et al. (2005) ATP mediates rapid microglial response to local brain injury in vivo. Nat Neurosci 8: 752-758.

243. Nimmerjahn A, Kirchhoff F, Helmchen F (2005) Resting microglial cells are highly dynamic surveillants of brain parenchyma in vivo. Science 308: 1314 1318.

244. Matsumoto Y, Ohmori K, Fujiwara M (1992) Microglial and astroglial reactions to inflammatory lesions of experimental autoimmune encephalomyelitis in the rat central nervous system. J Neuroimmunol 37: 23-33. 
Citation: Khoo MLM, Tao H, Ma DDF (2011) Mesenchymal Stem Cell-Based Therapies for Parkinson's Disease: Progress, Controversies and Lessons for the Future. J Stem Cell Res Ther S2:005. doi:10.4172/2157-7633.S2-005

245. Giulian D, Li J, Li X, George J, Rutecki PA (1994) The impact of microgliaderived cytokines upon gliosis in the CNS. Dev Neurosci 16: 128-136.

246. Singhal S, Lawrence JM, Bhatia B, Ellis JS, Kwan AS, et al. (2008) Chondroitin sulfate proteoglycans and microglia prevent migration and integration of grafted Muller stem cells into degenerating retina. Stem Cells 26: 1074-1082.

247. Remy S, Canova C, Daguin-Nerriere V, Martin C, Melchior B, et al. (2001) Different mechanisms mediate the rejection of porcine neurons and endothelial cells transplanted into the rat brain. Xenotransplantation 8: 136-148.

248. Kittler EL, McGrath H, Temeles D, Crittenden RB, Kister VK, et al. (1992) Biologic significance of constitutive and subliminal growth factor production by bone marrow stroma. Blood 79: 3168-3178.

249. Guba SC, Sartor Cl, Gottschalk LR, Jing YH, Mulligan T, et al. (1992) Bone marrow stromal fibroblasts secrete interleukin- 6 and granulocyte-macrophage colony- stimulating factor in the absence of inflammatory stimulation: demonstration by serum-free bioassay, enzyme-linked immunosorbent assay, and reverse transcriptase polymerase chain reaction. Blood 80: 1190-1198.

250.Czech KA, Ryan JW, Sagen J, Pappas GD (1997) The influence of xenotransplant immunogenicity and immunosuppression on host $\mathrm{MHC}$ expression in the rat CNS. Exp Neurol 147: 66-83.

251.Borel JF, Feurer C, Gubler HU, Stahelin H (1976) Biological effects of cyclosporin A: a new antilymphocytic agent. Agents Actions 6: 468-475.

252. Borel JF, Feurer C, Magnee C, Stahelin H (1977) Effects of the new antilymphocytic peptide cyclosporin A in animals. Immunology 32: 1017-1025.

253. Larsson LC, Czech KA, Brundin P, Widner H (2000) Intrastriatal ventra mesencephalic xenografts of porcine tissue in rats: immune responses and functional effects. Cell Transplant 9: 261-272.

254. Larsson LC, Frielingsdorf H, Mirza B, Hansson SJ, Anderson P, et al. (2001) Porcine neural xenografts in rats and mice: donor tissue development and characteristics of rejection. Exp Neurol 172: 100-114.

255. Wallgren AC, Karlsson-Parra A, Korsgren O (1995) The main infiltrating cell in xenograft rejection is a CD4+ macrophage and not a $T$ lymphocyte. Transplantation 60: 594-601.

256. Larsson LC, Czech KA, Widner H, Korsgren O (1999) Discordant neural tissue xenografts survive longer in immunoglobulin deficient mice. Transplantation 68: 1153-1160.

257. Barker RA, Ratcliffe E, McLaughlin M, Richards A, Dunnett SB (2000) A role for complement in the rejection of porcine ventral mesencephalic xenografts in a rat model of Parkinson's disease. J Neurosci 20: 3415-3424.

258. Cicchetti F, Fodor W, Deacon TW, van Horne C, Rollins S, et al. (2003) Immune parameters relevant to neural xenograft survival in the primate brain. Xenotransplantation 10: 41-49.

259. Wennberg L, Czech KA, Larsson LC, Mirza B, Bennet W, et al. (2001) Effects of immunosuppressive treatment on host responses against intracerebral porcine neural tissue xenografts in rats. Transplantation 71: 1797-1806.
260. Alemdar AY, Sadi D, McAlister V Mendez I (2007) Intracerebral cotransplantation of liposomal tacrolimus improves xenograft survival and reduces graft rejection in the hemiparkinsonian rat. Neuroscience 146: 213 224.

261.Chen X, McClurg A, Zhou GQ, McCaigue M, Armstrong MA, et al. (2007) Chondrogenic differentiation alters the immunosuppressive property of bone marrow- derived mesenchymal stem cells, and the effect is partially due to the upregulated expression of B7 molecules. Stem Cells 25: 364-370.

262. Liu CT, Yang YJ, Yin F, Wang X, Yu XH, et al. (2006) The immunobiologica development of human bone marrow mesenchymal stem cells in the course of neuronal differentiation. Cell Immunol 244: 19-32.

263. Isakova IA, Baker K, DuTreil M, Dufour J, Gaupp D, et al. (2007) Age- and dose- related effects on MSC engraftment levels and anatomical distribution in the central nervous systems of nonhuman primates: identification of novel MSC subpopulations that respond to guidance cues in brain. Stem Cells 25 3261-3270.

264. Fitch MT, Silver J (1997) Activated macrophages and the blood-brain barrier: inflammation after CNS injury leads to increases in putative inhibitory molecules. Exp Neurol 148: 587-603.

265. McKeon RJ, Jurynec MJ, Buck CR (1999) The chondroitin sulfate proteoglycans neurocan and phosphacan are expressed by reactive astrocytes in the chronic CNS glial scar. J Neurosci 19: 10778-10788.

266. Jones LL, Margolis RU, Tuszynski MH (2003) The chondroitin sulfate proteoglycans neurocan, brevican, phosphacan, and versican are differentially regulated following spinal cord injury. Exp Neurol 182: 399-411.

267. Fouad K, Schnell L, Bunge MB, Schwab ME, Liebscher T, et al. (2005) Combining Schwann cell bridges and olfactory-ensheathing glia grafts with chondroitinase promotes locomotor recovery after complete transection of the spinal cord. J Neurosci 25: 1169-1178.

268. Ourednik V, Ourednik J, Xu Y, Zhang Y, Lynch WP, et al. (2009) Cross-talk between stem cells and the dysfunctional brain is facilitated by manipulating the niche: evidence from an adhesion molecule. Stem Cells 27: 2846-2856.

269. Takayama H, Ray J, Raymon HK, Baird A, Hogg J, et al. (1995) Basic fibroblast growth factor increases dopaminergic graft survival and function in rat model of Parkinson's disease. Nat Med 1: 53-58.

270. Bhang SH, Lee YE, Cho SW, Shim JW, Lee SH, et al. (2007) Basic fibroblas growth factor promotes bone marrow stromal cell transplantation-mediated neural regeneration in traumatic brain injury. Biochem Biophys Res Commun 359: $40-45$

271. Nakao N, Frodl EM, Duan WM, Widner H, Brundin P (1994) Lazaroids improve the survival of grafted rat embryonic dopamine neurons. Proc Natl Acad Sci U S A 91: 12408-12412.

272. Fang B, Shi M, Liao L, Yang S, Liu Y, et al. (2004) Systemic infusion of FLK1(+) mesenchymal stem cells ameliorate carbon tetrachloride-induced liver fibrosis in mice. Transplantation 78: 83-88. 